\title{
Tackling the Moving Mutant Target: Taxifolin Derivatives as Novel Putative E571K Exportin-1 Inhibitors for KRAS-mutant Lung Adenocarcinoma Therapy
}

Temidayo Olamide Adigun ${ }^{1 *}$, Oluwatobi Ayodeji Medayedupin ${ }^{1}$, Ireoluwa Yinka Joel ${ }^{1}$, Idowu Yetunde Fakolujo $^{1}$, Bankole Emmanuel Ofeniforo ${ }^{1}$, Faith Oluwadara Bankole ${ }^{5}$, Adedayo Pius Omoniyi $^{3}$, Olalekan Bukunmi Ogunro ${ }^{4}$, Adebimpe Ayomide Agunlejika ${ }^{2}$, Oluwatobi Cynthia Omoyeni $^{2}$, Joy Omowunmi Bamidele ${ }^{2}$, Adetola Abiola Ajayi ${ }^{2}$

Corresponding author: prothesis4life@gmail.com (Temidayo Olamide Adigun)

${ }^{1}$ Department of Biochemistry, Faculty of Life Sciences, University of Ilorin, Ilorin, Nigeria

${ }^{2}$ Department of Science and Laboratory Technology, School of Pure and Applied Sciences, Federal Polytechnic Ilaro, Ilaro, Nigeria

${ }^{3}$ Department of Biochemistry, School of Sciences, Federal University of Technology Akure, Akure, Nigeria

${ }^{4}$ Department of Biological Sciences, KolaDaisi University, Ibadan, Nigeria

${ }^{5}$ Medical Center, Federal Polytechnic Ilaro, Ilaro, Nigeria

\begin{abstract}
Aim: To establish, through molecular modelling, safe and clinically acceptable putative antagonists of E571K-mutated exportin-1 among the bioactive compounds in various parts of Juglans mandshurica.

Methods: The bioactive compounds were subjected to compendium of druglikeness and leadlikeness filter workflows prior to docking of the resultant compounds into E571K exportin-1 active site using PyRx AutoDock vina to establish their binding affinity and interaction profile. The evolutionary algorithm of Osiris property explorer DataWarrior software as well as lead-likeness filter were employed for generation of novel non-promiscuous analogues of the lead compound with better putative selectivity and clinical acceptability as E571K Exportin-1 antagonists.
\end{abstract}


Results: The findings of this study present taxifolin as the putatively effective and lead-like E571K Exportin-1 inhibitor with high potential of qualifying for clinical evaluation but is associated with high promiscuity tendency in high throughput screening. The evolutionary derivation of novel analogues of the compound, however, results in the generation of putatively non-promiscuous, non-toxic, and lead-like E571K Exportin-1 antagonists with high synthetic accessibility and clinical developability for evaluation in the strategy for treatment of drug-resistant KRAS-mutant lung adenocarcinoma condition.

Keywords: KRAS-mutant lung adenocarcinoma, E571K exportin-1, Taxifolin, Molecular modelling.

\subsection{Introduction}

The positive association between the recurring poor prognostic drug resistance and their varied genomic mutations widely emphasizes its clinical relevance in the various chemotherapeutic strategies for reducing cancer-associated morbidities and mortalities ${ }^{66,67}$. This include the missense single nucleotide gain-of-function E571K mutation of exportin-1 gene (XPO1) that thereby codes for positively charged lysine instead of negatively charged glutamate residues in exportin-1 and abnormally elevates its affinity for nuclear export signals (NES) ${ }^{68,17}$.

The deregulation of exportin-1 (also known as chromosomal region maintenance 1), as a major RanGTP-driven exporter of more than 1050 human NES-bearing proteins (including tumour suppressors such as p53, BRCA1 etc. ${ }^{69}$ and protooncogenes) as well as several RNA species ${ }^{70,71}$ across the cell nucleo-cytoplasmic partition, is an active driver of several oncogenic conditions including the highly untreatable KRAS-mutant lung adenocarcinoma ${ }^{72,73}$. 
Although the recurrence of exportin-1 E571K mutation is mostly reported in some haematological malignancies ${ }^{74,67}$, while Taylor et al. (2019) opined its rarity in solid tumours; there are currently reported $0.13 \%$ of XPO1 E571K mutation cases in a solid tumour such as KRAS-mutant lung adenocarcinoma $^{53,75}$, and developing effective selective inhibitor of nuclear export signals (SINEs) for tackling the isolated E571K-mutated exportin-1 is a plausible strategy with potential significance in improving the prognosis of this highly untreatable condition. Indeed, several currently developed selective inhibitors of nuclear export signals (SINEs), including the clinically evaluated selinexor (KPT-330), KPT-185 etc., has been suggested as effective inhibitors of both the mutated and wild type XPO1 protein but remain limited in potency as single agent and/or safety in single or combination therapy or both ${ }^{51,18}$.

We intend to find novel selective inhibitor (s) of nuclear export signals (SINEs), through molecular modelling, in this study that can effectively inhibit E571K-mutated exportin-1 with better potency and safety profile among the compounds reportedly identified in several studies $32,41,21,35$, $61,60,33,62,45,57,28,55$ from various parts of Juglans mandshurica - a scientifically proven anticancer plant in several tumour cell lines ${ }^{36,27}$. This concept is validated by the fact that natural products are constituted of complex chemotypes with favourable safety profile and promising potential for discovery of novel nuclear export inhibitors ${ }^{76}$.

\subsection{Methods}

\subsection{Protein Preparation}

The 3D coordinate files of crystal structure of an unliganded human (homo sapiens) chromosomal region maintenance 1 (E571K)-Ran-RanBP1 complex (PDB ID: 6X2O) was retrieved from the 
Research Collaboratory for Structural Bioinformatics (RCSB) protein data bank (http://www. rcsb.org), visualized using the Schrodinger molecular graphics program PyMol® and prepared using Schrodinger maestro protein preparation wizard. Briefly, the Ran-RanBP1 complex (chain A and B) were deleted while the remainder (chain C) was prepared under OPLS2005 force field at $\mathrm{pH}$ of 7.0 \pm 2.0 . All steric clashes were corrected, hydrogen bond order fixed, while the missing side chains and loops were corrected using prime. Disulfide bonds were created, water molecules

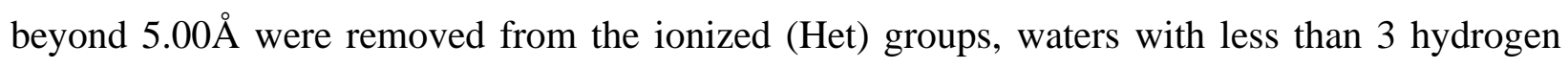
bonds to non-waters were deleted while the bond orders were assigned. The charge cutoff for polarity was 0.25 . This was further minimized by addition of polar hydrogens and merging of nonpolar ones using the plugged-in version of open babel software of PyRx AutoDock Vina version 0.8 and Gasteiger charges were computed using AutoDock $4.2^{26}$.

\subsection{Ligand Preparation}

The simplified input line entry system (SMILES) representations of identified Juglans mandshurica compounds $\mathrm{s}^{32,41,21,35,61,60,33,62,45,57,28,55}$ was obtained from PubChem database (https://pubchem.ncbi.nlm.nih.gov) while those with unavailable information were designed using ChemAxon Marvin Sketch. These were co-catenated and converted to MDL MOL structure description file format (SDF) using Osiris Property Explorer DataWarrior version 5.2.1. The physicochemical properties of the compounds were calculated and filtered based on the cut-off involving Lipinski's rule, topological surface area (TPSA) $\leq 140 \AA$, as well as the number of rotatable bonds $\leq 10$. The compounds were also filtered further based on their putative tumorigenicity, mutagenicity, irritant properties, as well as druglikeness while the remaining compounds were converted to PDBQT file using PyRx tool to generate atomic coordinates through 
the optimization algorithm set at the universal force field parameters. The 2D SDF format of the standard compound (KPT-185) evaluated in this study was also obtained from PubChem and prepared with similar workflow.

\subsection{Ligand Docking}

We calculated the binding energies of the obtained compounds with the target binding site by single blind docking simulation using PyRx AutoDock Vina version 0.8 with further energy minimization through the forcefield-based scoring function ${ }^{77}$. The PyRx AutoDock Vina, operating on the basis of assumably fixed three-dimensional target and flexible ligand structure ${ }^{54}$, employs the Broyden-Fletcher-Goldfarb-Shanno method in its multithread gradient optimization approach of iterated local search global optimizer algorithm ${ }^{44,2}$. The grid box resolution was centered at $12.0200 \times-38.4570 \times 337.6422$ along the $\mathrm{x}, \mathrm{y}$ and $\mathrm{z}$ axes respectively at the grid dimension of $25 \AA$ x $25 \AA$ x $25 \AA$ defining the binding site and the comparative analysis of resulting interaction between the obtained Juglans compounds and the standard at the target binding site were obtained within the same docking grid box dimension.

\subsection{Visualization of Docking Results}

The ligand interactions at the target binding pocket and their three-dimension (3D) interaction with the target residues were visualized using Schrodinger Python Molecular graphics interface $\left(\mathrm{PyMol}{ }^{\circledR}\right)$ version 2.2.0 software while the two-dimension (2D) ligand - residue interactions were obtained using BIOVIA Discovery Suite version 17.2.0.16349. The local minimum energy conformation binding mode of the compounds are regarded as the optimal binding pose at the target binding site in this study ${ }^{56,46}$. 


\subsection{Validation of Docking Study}

\subsubsection{Validation of Docking Protocol}

The docking protocol of this study was validated by redocking of the same standard compound into the same target binding site and examining the relative binding pose of the ligands using the Python Molecular graphics interface (PyMol®) software.

\subsubsection{Validation of Docking Algorithm}

The binding energy calculation algorithm applied in this study was validated by comparative analysis of docking scores of the hits and the standard compound (KPT-185) in other different docking algorithms including Molegro virtual docker (PLANTS scoring function), LeDock, and iGEMDock.

\subsubsection{Molegro Virtual Docker (PLANTS Scoring Function)}

We employ the iterated simplex search algorithm (based on Nelder-Mead algorithm) with ant colony optimization component ${ }^{4}$ of Molegro Virtual Docker for simulation of interaction between the E571K Exportin-1 active site and the hit compounds in this study, while the protein-ligand ANTS (PLANTS) scoring function with GRID $^{23}$ was used to calculate the potential energy values on a cubic grid prior to docking.

\subsubsection{LeDock}

We docked each of the three hits and the standard (KPT-185) into the target active site and calculated the docking scores through combination of simulated annealing and genetic algorithm for each ligand pose, orientation, and rotatable bond optimization in LeDock ${ }^{63}$, while the scoring function is on the basis of transferable and accurate energy function consisting of van der Waals interaction energy and a unique empirical-based hydrogen bonding energy ${ }^{64}$. 


\subsubsection{3 iGEMDock}

The various possible conformations of each of the hits were also obtained through the genetic evolutionary algorithm of iGEMDock ${ }^{59,25}$ in which we considered 66 generations per ligand with population size of 200 random individual offspring ligands per generation while the fitness, defined by empirical summation of partial contributory energy of the formed van der Waals, hydrogen bonding, and electrostatic interactions, were calculated for each of the flexibly docked structures at the E571K Exportin-1 active site. We set the ligand hydrophobic and electrostatic preference at 1.00 , the number of solutions employed is 2 , and only ligands with interactions within the binding site radius of $8.00 \AA$ were employed in the GEMDock scoring function calculations that also include the ligand intramolecular energies for total energy calculation in this study.

\subsection{Pharmacokinetics and Toxicity Profiling}

We employed a compendium of workflow involving the web-based predictive tool SwissADME (http://www.swissadme.ch/index.php), and DataWarrior to profile both the hits and the lead compound derivatives in this study for their absorption, distribution, metabolism, excretion, and toxicity properties.

\subsection{De novo Generation of Lead Compound Derivatives}

An evolutionary library of derivatives of the lead compound was built in this study by creating compounds similar to current standard-of-care drugs for 50 generations using the Osiris property explorer DataWarrior software in which the substructures of the parent compound at the turn of each generation were randomly left untouched. The SkelSpheres descriptors were used in the generation of 128 compounds per generation while the maximum of 8 compounds were allowed to survive a generation. 


\subsection{Results and Discussion}

\subsection{Compounds Obtained}

The total of 123 compounds reported by some studies ${ }^{32,41,21,35,61,60,33,62,45,57,28,55}$ was retrieved in this study while a total of five (5) predictably drug-like and non-toxic compounds (Table 1) were recovered following the pre-filtering workflow (See 2.2) on Osiris property explorer. Compound 30, 31, and 54 were the identified but non-designated compounds from Juglans mandshurica with currently no structural information in the PubChem database, the compound with the ChemBL ID: 463247 is tetrahydro-2-(4-hydroxy-3-methoxyphenyl)-6-(alpha,4-dihydroxyphenethyl)-4Hpyran-4-ol while the first-generation SINE compound KPT-185 (PubChem CID: 53495165) was evaluated as the standard compound.

Table 1: Simplified Molecular Input Line Entry System Representation of Retrieved Juglans mandshurica Following Drug-likeness and Toxicity Filters

\begin{tabular}{|c|c|c|c|c|c|}
\hline Compound & SMILES & $\begin{array}{c}\text { Drugliken } \\
\text { ess }\end{array}$ & Mutagenicity & $\begin{array}{c}\text { Tumorigenicit } \\
\mathbf{y}\end{array}$ & Teratogenicity \\
\hline Taxifolin & $\begin{array}{c}\mathrm{O}=\mathrm{C} 1 \mathrm{c} 2 \mathrm{c}(\mathrm{OC}(\mathrm{C} 10) \mathrm{c} 1 \mathrm{cc}(0) \mathrm{c}(\mathrm{cc} 1) \\
\mathrm{O}) \mathrm{cc}(\mathrm{cc} 2 \mathrm{O}) \mathrm{O}\end{array}$ & 0.44477 & None & None & None \\
\hline Malic Acid & O=C(O)[C@@H](O)CC(=O)O & 0.70851 & None & None & None \\
\hline $\begin{array}{c}\text { Compound } \\
\mathbf{3 0}\end{array}$ & $\begin{array}{c}\mathrm{O}=\mathrm{C}(\mathrm{O}) \mathrm{C}(\mathrm{O})(\mathrm{C}(=\mathrm{O}) / \mathrm{C}=\mathrm{C} / \mathrm{c} 1 \mathrm{ccc}(\mathrm{cc} \\
\text { 1)O } \mathrm{C}(\mathrm{O}) \mathrm{CO}\end{array}$ & 1.0433 & None & None & None \\
\hline $\begin{array}{c}\text { Compound } \\
31\end{array}$ & $\begin{array}{c}\mathrm{O}=\mathrm{C} 1 \mathrm{c} 2 \mathrm{c}(\mathrm{cccc} 2) \mathrm{C}[\mathrm{C} @ \mathrm{OH}](\mathrm{C} 1(\mathrm{O}) \\
\mathrm{O}) \mathrm{O}\end{array}$ & 0.88711 & None & None & None \\
\hline $\begin{array}{c}\text { Compound } \\
54\end{array}$ & $\begin{array}{c}\mathrm{O}=\mathrm{C} 1 \mathrm{c} 2 \mathrm{c}(\mathrm{O}) \operatorname{cccc} 2 \mathrm{C} 2(\mathrm{CC} 1 \mathrm{C}(\mathrm{c} 1 \mathrm{c} 2 \mathrm{c} \\
\mathrm{c}(\mathrm{c}(\mathrm{c} 1) \mathrm{O}) \mathrm{O}) \mathrm{CC}(=\mathrm{O}) \mathrm{O}) \mathrm{O}\end{array}$ & 0.75027 & None & None & None \\
\hline $\begin{array}{c}\text { ChemBL } \\
\text { ID: } 463247\end{array}$ & $\begin{array}{c}\mathrm{O} 1 \mathrm{C}(\mathrm{c} 2 \mathrm{cc}(\mathrm{OC}) \mathrm{c}(\mathrm{cc} 2) \mathrm{O}) \mathrm{CC}(\mathrm{CC} 1 \mathrm{C}( \\
\mathrm{O}) \mathrm{Cc} 1 \mathrm{ccc}(\mathrm{cc} 1) \mathrm{O}) \mathrm{O}\end{array}$ & 0.71056 & None & None & None \\
\hline KPT-185 & $\begin{array}{c}\mathrm{FC}(\mathrm{F})(\mathrm{F}) \mathrm{c} 1 \mathrm{cc}(\mathrm{OC}) \mathrm{cc}(\mathrm{c} 1) \mathrm{c} 1 \mathrm{nn}(\mathrm{cn} \\
1) / \mathrm{C}=\mathrm{C} / \mathrm{C}(=\mathrm{O}) \mathrm{OC}(\mathrm{C}) \mathrm{C}\end{array}$ & -9.3576 & High & None & Low \\
\hline
\end{tabular}


The druglikeness score of a compound, calculated from the compound toxicity descriptors and the degree at which it contains predominantly the fragments frequently present in commercially available drugs, helps validate its potential as a drug candidate ${ }^{78}$. The prefiltered five compounds from Juglans mandshurica in this study (Table 1) predictively shows no risk of tumorigenicity, mutagenicity, and teratogenicity and irritant properties with quantitative estimate of druglikeness (druglikeness score) range of 0.44477 to 1.0433 in this study. This, though may not be well balanced with other requisite properties for compound druggability ${ }^{48,78}$, presents them as displaying constitution of at least one of the available core fragments and possible reconstructed fragments generated by the fragmentist-based approach of López-López et al. $(2019)^{78}$, involving shredded 3,300 traded drugs and 15,000 commercially available (Fluka) chemicals.

Optimal cell permeability of a compound, and consequentially its bioavailability and potency, is an inverse function of summation of its polar atomic surface area ${ }^{79}$. The total polar surface area (TPSA) of the prefiltered five compounds from Juglans mandshurica in this study (Table 2) is in the square angstroms value range of 77.76-135.29, thereby obeying the drug-like model rules of Veber et al. (2002) $)^{80}$ and Muegge et al. $(2001)^{81}$. The cell permeability potential of the compounds however notably precludes, due to their TPSA values greater than 60 square angstroms (Table 2), the potential of central nervous effects and toxicities via their blood-brain barrier impenetrability.

The pivotal balance between a compound molecular weight and other descriptive features of its bioavailability essentially defines its potency and safety profile. This is because increased molecular weight positively correlates with elevated bioactivity but inversely associates with gastrointestinal absorption ${ }^{78}$. The molecular weight of the five compounds (134.09-360.41) retrieved in this study (Table 2) falls within the general consensus range of $160 \leq$ molecular weight $<500$ for predictably bioavailable and drug-like compounds ${ }^{82,83}$, as well as represents the fact that 
more than $80 \%$ of all traded drugs has molecular weight below 450, as demonstrated by LópezLópez et al. (2019).

A definable ligand-target specificity is a function of the compound spatial orientation and geometry within the target binding site ${ }^{19,84}$. The molecular shape index range $(0.385-0.667)$ of the retrieved compounds in this study (Table 2) shows the various parts of Juglans mandshurica as rich natural sources of compounds with complex chemotypic scaffolds. Furthermore, the modal value range of the retrieved compounds being $\leq 0.5$ reveals the highest number of the retrieved compounds possess significant three-dimensional (non-flat) shape space coverage (which positively correlates with broad biological activity ${ }^{50,12}$ similar to most of current standard-of-care drugs.

The molecular complexity score of a compound, a measure of combination of complexity metrics involving single cluster of its fragment structural fingerprint, accounts for its aromatic ring numbers and sp3 hybridized carbon fractions (Fsp3) $)^{39,85}$. It is an inverse function of the compound promiscuity potential, and safety profile but positively associates with its clinical trial success rate, and developability ${ }^{38,37}$ on a specified scale of $0.1-1.5^{22,85}$. The molecular complexity score range (0.621-0.997) of the retrieved compounds in this study (Table 2) presents them as having fraction number of chiral sp3 atoms (Fsp3) within the range constituting currently traded drugs; a prerequisite for their potential clinical developability into safe, potent, and E571K Exportin-1selective inhibitors.

The molecular flexibility scores of the retrieved compounds in this study (Table 2), a function of their complexity, changeable dihedral bond angles, and geometry weighting factors ${ }^{86,87}$, are in the range of $0.136-0.751$ on the scale of 0.0 (flexible) to 1.0 (completely rigid). This plays crucial role 
in defining the potential relative binding capacities of the compounds in the target active site as a ligand conformational rigidity (due to fewer rotatable bonds) positively correlates with its target binding affinity potential ${ }^{29,15}$.

Table 2: Physical Properties of Resultant Prefiltered Compounds

\begin{tabular}{cccccc}
\hline $\begin{array}{c}\text { Molecule } \\
\text { Name }\end{array}$ & $\begin{array}{c}\text { Polar } \\
\text { Surface } \\
\text { Area }\end{array}$ & $\begin{array}{c}\text { Molecular } \\
\text { Weight }\end{array}$ & $\begin{array}{c}\text { Molecular } \\
\text { Shape } \\
\text { Index }\end{array}$ & $\begin{array}{c}\text { Molecular } \\
\text { Flexibility }\end{array}$ & $\begin{array}{c}\text { Molecular } \\
\text { Complexity }\end{array}$ \\
\hline Taxifolin & 127.45 & 304.253 & 0.50 & 0.267 & 0.852 \\
\hline Malic Acid & 94.83 & 134.087 & 0.67 & 0.751 & 0.621 \\
\hline $\begin{array}{c}\text { Compound } \\
\mathbf{3 0}\end{array}$ & 135.29 & 282.247 & 0.60 & 0.563 & 0.708 \\
\hline $\begin{array}{c}\text { Compound } \\
\mathbf{3 1}\end{array}$ & 77.76 & 194.185 & 0.50 & 0.136 & 0.761 \\
\hline $\begin{array}{c}\text { Compound } \\
\mathbf{5 4}\end{array}$ & 135.29 & 356.329 & 0.38 & 0.292 & 0.997 \\
\hline $\begin{array}{c}\text { ChemBL } \\
\text { ID: 463247 }\end{array}$ & 99.38 & 360.405 & 0.58 & 0.512 & 0.776 \\
\hline KPT-185 & 66.24 & 355.32 & 0.56 & 0.495 & 0.810 \\
\hline
\end{tabular}

\subsection{Ligand Docking}

Potency and safety limitations abound around the potential effects of current SINE compounds as E571K-mutated Exportin-1 inhibitors in KRAS-mutant lung adenocarcinoma condition ${ }^{68,18}$. The molecular docking simulation approach is a behavioural characterization of the interaction between potential small molecule inhibitors of druggable targets and the possible biochemistry of their potential effect (s) through phenotypic screening of the drug-like compounds ${ }^{88}$. 
The PyRx AutoDock vina screening of the drug-like compounds retrieved from Juglans mandshurica in this study (Figure 1) showed compound 54 and the compound with ChemBL ID: 463247 as having relatively higher binding affinities $(-5.5 \mathrm{kcal} / \mathrm{mol}$ to $-5.6 \mathrm{kcal} / \mathrm{mol})$ when compared with that of KPT-185 as the standard compound, thereby suggesting relatively higher bioactivity efficacy potential of these hits as E571K exportin-1 inhibitors. It is also worthy of note that although taxifolin showed comparatively equivalent binding affinity to that of KPT-185 (-5 $\mathrm{kcal} / \mathrm{mol}$ ) in this study (Figure 1); it displays relatively lower molecular flexibility score (Table 2) with the consequential tendency of comparatively advancing its efficacy due to its rigiditymediated lower entropy loss at the E571K exportin-1 active site. 


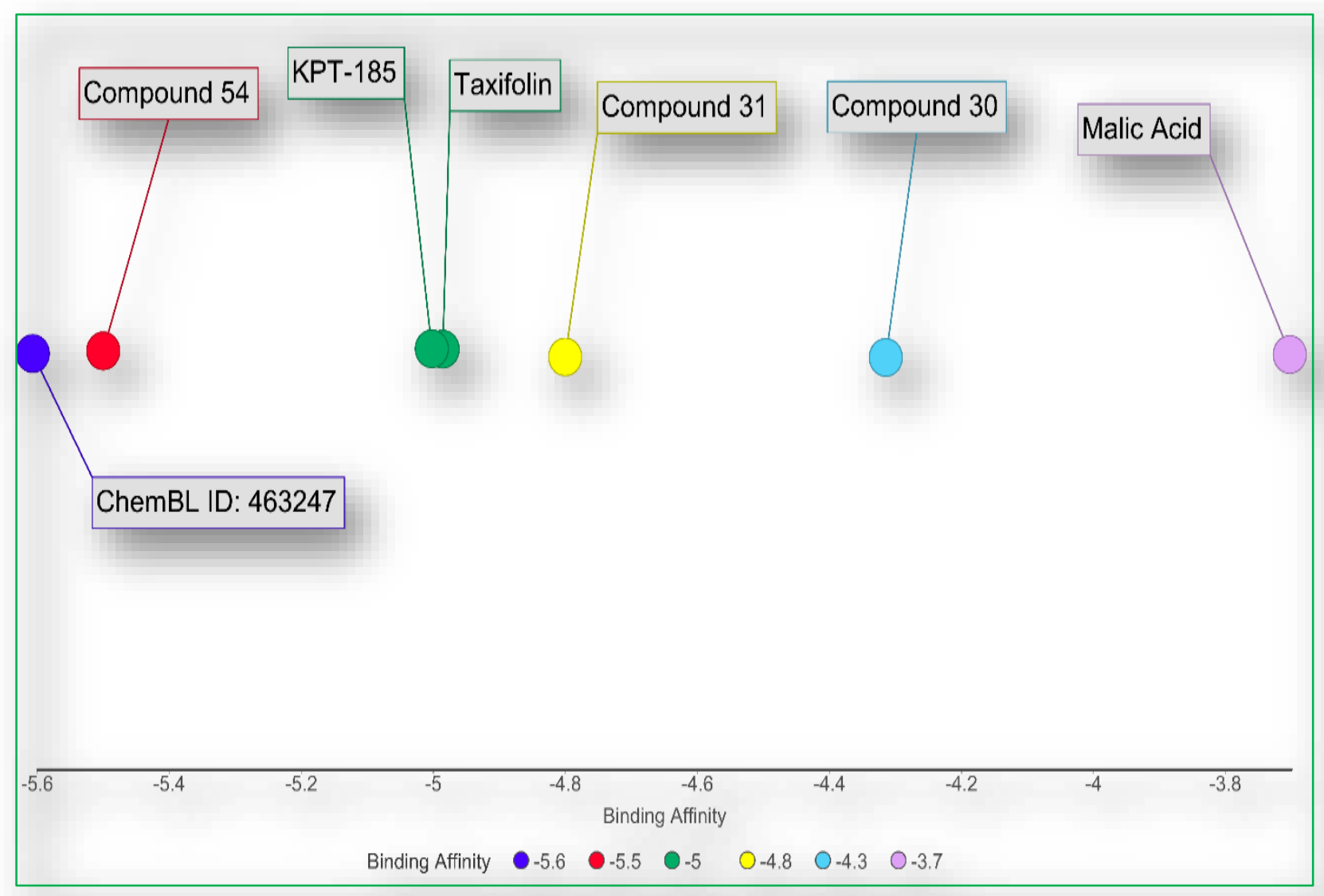

Figure 1: Graphical Representation of Docking Score (in kcal/mol) of Retrieved

\section{Compounds}

\subsection{Study Validation}

\subsubsection{Validation of Docking Protocol}

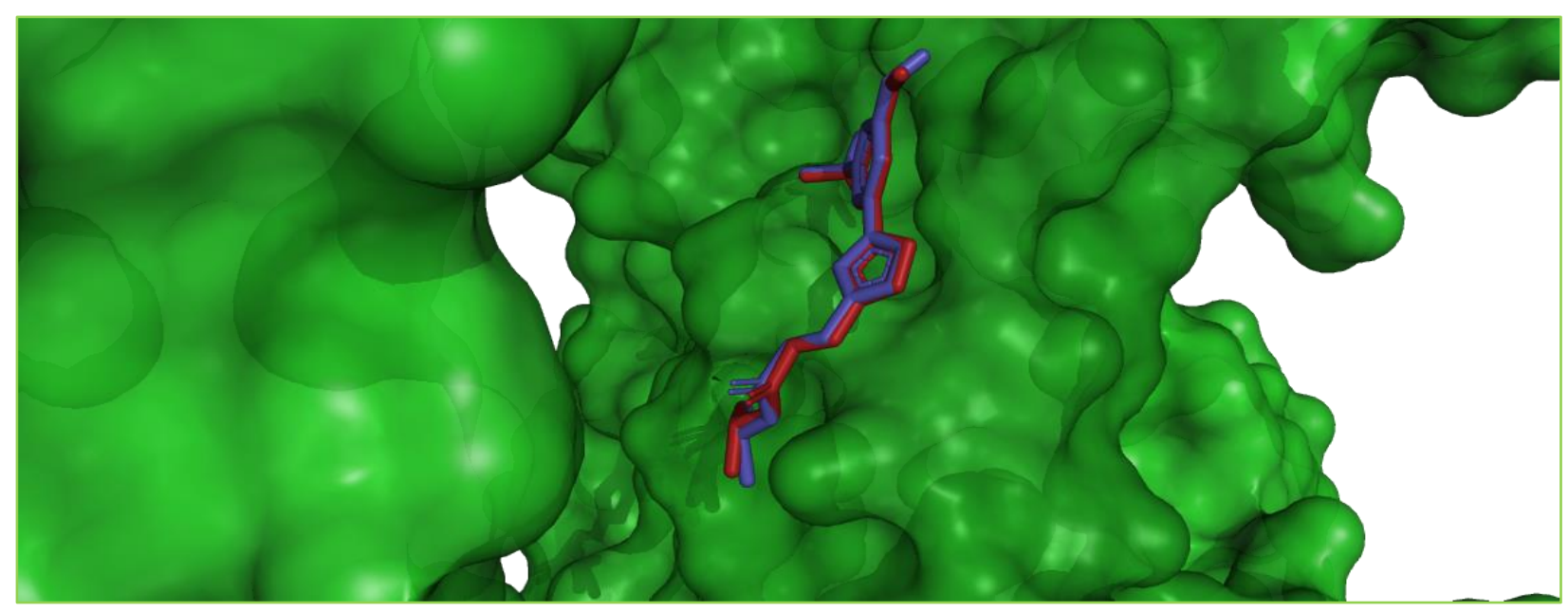




\section{Figure 2: Superimposition of Redocked KPT-185 at the Target Binding Site}

The superimposition of relative binding poses of the redocked KPT-185 at the E571K Exportin-1 active site (Figure 2) in this study shows the ligand docking procedure in this study as valid, thereby rendering the various docking scores as accurate.

\subsubsection{Validation of Docking Algorithm}

The results from other docking algorithms (Table 3) further reveals comparative higher binding energies of the hit compounds than that of KPT-185 similar to the findings of the study executed using PyRx AutoDock vina, thereby confirming the binding affinities attributed to each of the hits in this study.

Table 3: Comparative Scores of Different Docking Algorithms with the Vina Docking Score

\begin{tabular}{|c|c|c|c|c|}
\hline Ligand/Algorithm & $\begin{array}{c}\text { PyRx } \\
\text { AutoDock } \\
\text { Vina } \\
\text { (kcal/mol) }\end{array}$ & $\begin{array}{c}\text { LeDock } \\
(\mathbf{k c a l} / \mathbf{m o l})\end{array}$ & $\begin{array}{c}\text { Molegro } \\
\text { Virtual } \\
\text { Docker } \\
\text { PLANTS }\end{array}$ & $\begin{array}{c}\text { iGEMDock } \\
\text { (kcal/mol) }\end{array}$ \\
\hline Taxifolin & -5.0 & -4.39 & --50.96 & -125.56 \\
\hline Compound 54 & -5.5 & -5.01 & -52.30 & -126.98 \\
\hline $\begin{array}{c}\text { ChemBL ID: } \\
\text { 463247 }\end{array}$ & -5.6 & -4.37 & -49.50 & -129.00 \\
\hline KPT-185 & -5.0 & -4.20 & -44.39 & -97.74 \\
\hline
\end{tabular}




\subsection{Interaction Between E571K Exportin-1 and Hit Compounds}

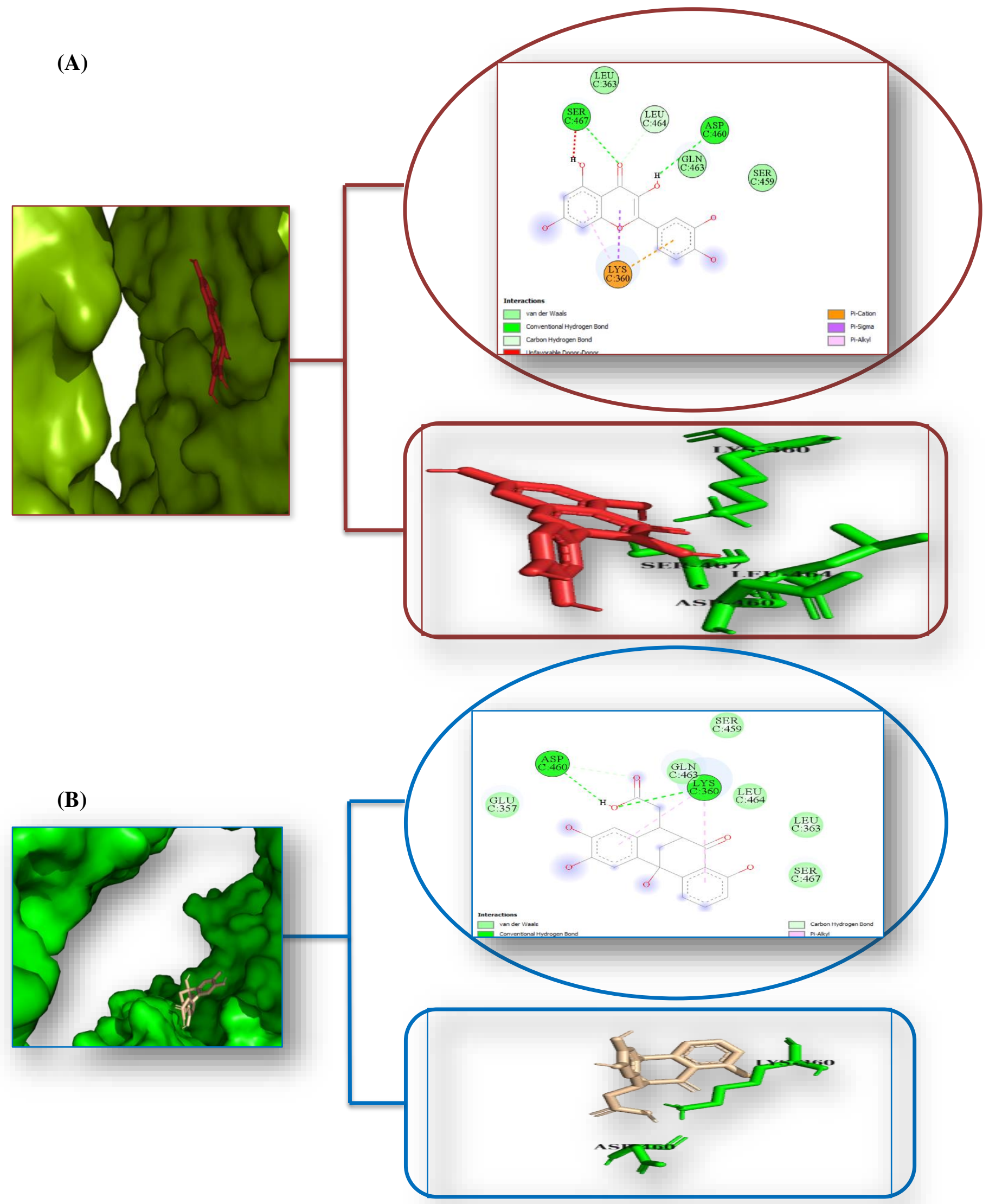


(C)

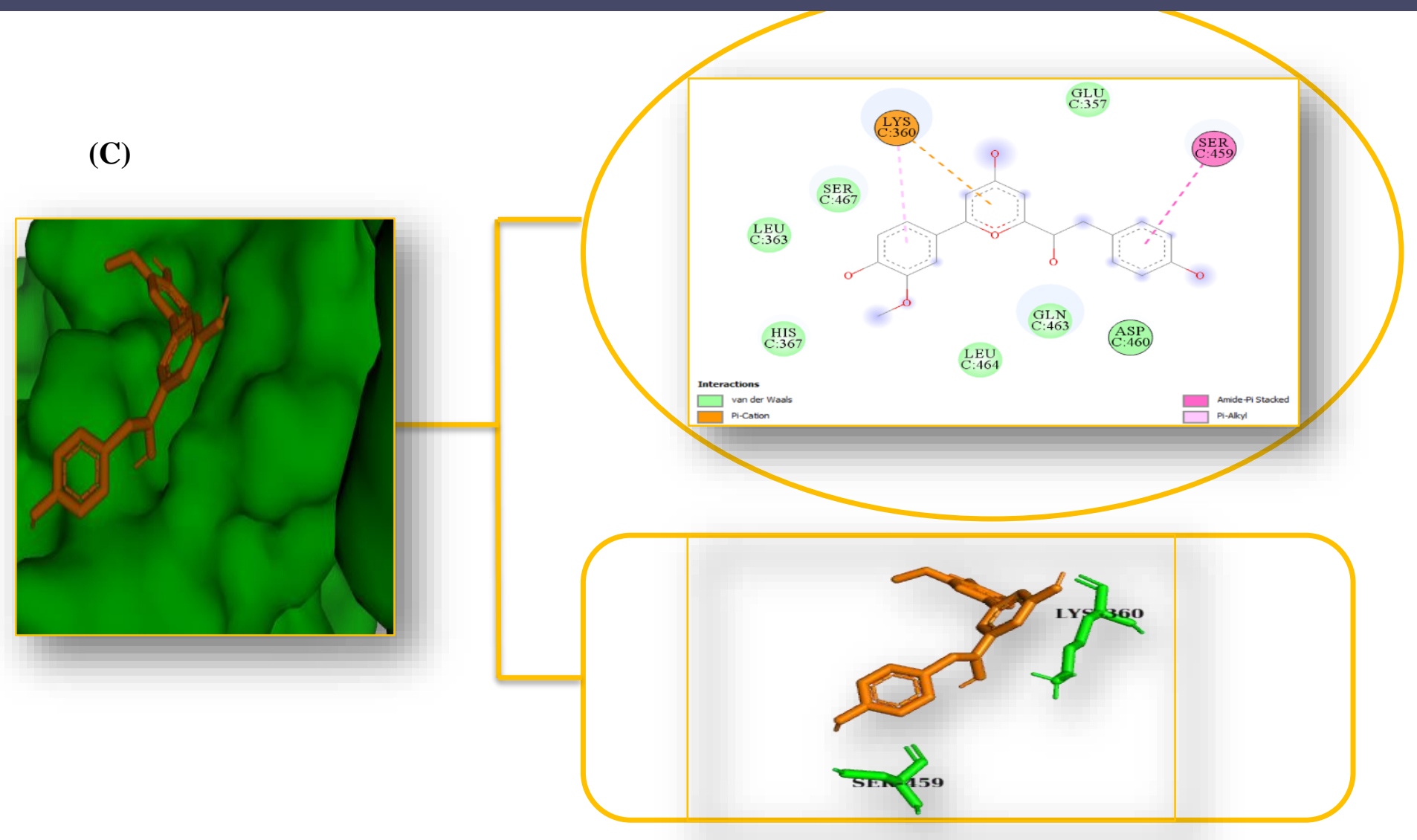

(D)

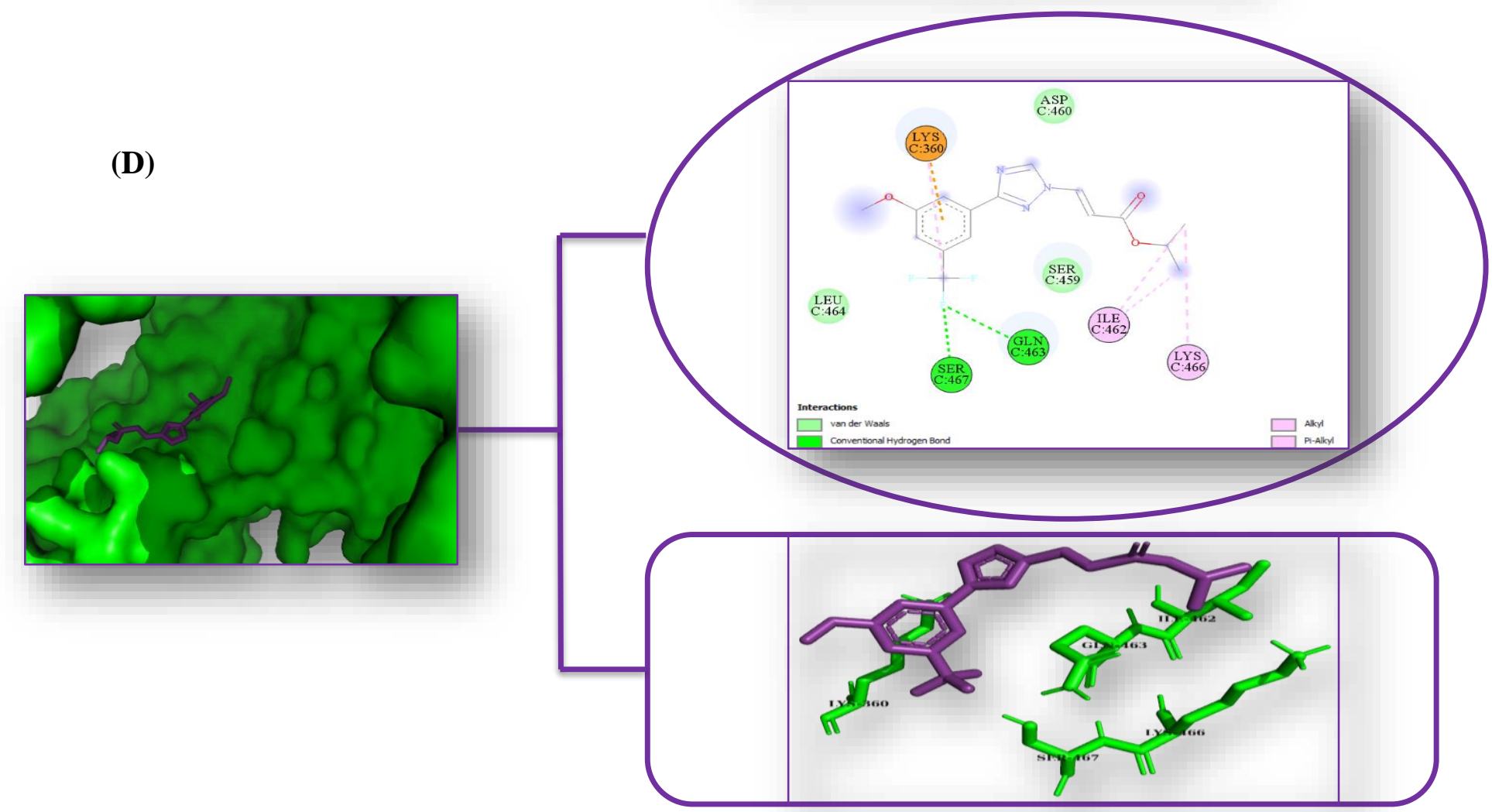

Figure 3: Representation of Ligand-Target Interaction. (A) Interaction between Taxifolin and E571K Exportin-1 (B) Interaction between Compound 54 and E571K Exportin-1 (C) Interaction between ChemBL ID: 463247 and E571K Exportin-1 (D) Interaction between KPT-185 and E571K Exportin-1 
The binding energy and, subsequently, bioactivity of a drug entity at the target active site is defined by the type and number of its interaction within the target active residues ${ }^{89}$. The secondary ammonium ion in the active site lysine residue of E571K Exportin-1 commonly distorts the $\pi$ electron cloud of the aromatic ring in the three hit compounds (taxifolin, compound 54, compound with ChemBL ID: 463247) as well as KPT-185 in this study, thereby resulting in the formation of electrostatic Pi-cation dipole moment (Figure 3), which might have potential significant role in the mechanism of inhibition of both wild and mutated type of exportin-1 by SINE compounds.

Taxifolin, however, formed an additional hydrophobic Pi-sigma bond and conventional hydrogen bond (Figure 3A) with Lys 360 and Asp 460 residues respectively while both compound 54 (Figure 3B) and compound with ChemBL ID: 463247 (Figure 3C) formed an additional hydrophobic Pialkyl bond with the active lysine 360 residue. It is also noteworthy that taxifolin formed additional conventional hydrogen bond (comparably to KPT-185) with the active site serine residue 467, albeit with additional unfavourable donor-donor bond (Figure 3A) that may however potentially affects the drug-like entity activity stability through repulsive reduction of the ligand-protein complex as deduced by Samant et al. (2019) ${ }^{90}$. Hydrogen bonding interactions (between the E571K Exportin-1 active site lysine 360, aspartate 460, serine 467 residues and the atomic partial charges of taxifolin, compound 54, as well as KPT-185 in this study (Figure 3)) positively associates ${ }^{90}$ with significant target-ligand complex stability and bioactivity of the drug-like entities at the target active site. Furthermore, the hydrophobic interactions (Figure 3) of the drug-like entities possess significant putative contributory role in entropy increase-mediated overall binding energy elevation, through displacement of water molecules in ordered layers within $3 \AA$ of E571K Exportin-1 active site. 


\subsection{Pharmacokinetics, Toxicity, and Lead-likeness Profile of Hit Compounds}

The potency and safety profile of an orally bioavailable small molecule drug entity, a function of its pharmacokinetic profile, is partially defined by its lipophilicity-mediated gastrointestinal permeability and metabolism ${ }^{5}$. This study (Table 4) reveals the three hit compounds, including taxifolin, compound 54, and compound with ChemBL ID: 463247), as highly prone to gastrointestinal (GIT) absorption with comparatively similarity to that of KPT-185. Furthermore, the non-inhibition of cytochrome P450 enzyme (CYP) isoforms 1A2, 2C9, 2C19, 2D6, and 3A4 (metabolizing about $50 \%-90 \%$ of current drugs in the liver ${ }^{58,9,1}$ by the three hit compounds (with the exception of compound with ChemBL ID: 463247 on CYP 2D6) have plausible contributory role in the dose-bioavailability balance adjustment and significant toxic metabolite production avoidance of the putative inhibitors en route the action site while the inhibition of these CYP isoforms by KPT-185 (Table 4) may be playing significant role in the development of some of its associated toxicities (due to drug-drug interaction or accumulation) as well as its reportedly poor pharmacokinetic profile by Etchin et al. (2012) and Lapalombella et al. (2012) ${ }^{14,31}$. It is however noteworthy that both the three hit compounds and KPT-185 in this study (Table 4) does not significantly inhibits CYP3A4; an enzyme responsible for degradation of most drug entities in the liver.

The blood brain barrier (BBB), dynamically interfacing the blood and brain, prevents toxic xenobiotics entry into the brain endothelium as well as supply it with requisite nutrients while the P-glycoprotein receptor-mediated transport system plays vital role in the outflux of unwanted xenobiotics from the BBB and several other organs $s^{6,24}$. The three hit compounds, unlike KPT-185, does not permeate the blood-brain barrier in this study (Table 4), thereby showing very low potential adverse clinical effects on the brain by the hit compounds in KRAS-mutant lung 
adenocarcinoma therapy. Although this study reveals KPT-185 as blood-brain barrier permeant; it is noteworthy to determine the comparative threshold in vivo at which it may induce neurotoxic side effects during the disease therapy. Also, this may alternatively associate with its ability to confer neuroprotection against xenobiotics-induced axonal damage as reported by Haines et al. $(2015)^{20}$. Only taxifolin, however, showed the properties of significantly less prone to Pglycoprotein receptor-mediated outflux (comparably similar to KPT-185) in this study (Table 4) and can play significant role in its high GIT absorbability-mediated biodistribution model; a feature made pronounced by its non-blood-brain barrier permeability. 
Table 4: Absorption and Metabolic Profile of Hit Compounds

\begin{tabular}{|c|c|c|c|c|}
\hline Compound ID /Property & Taxifolin & $\begin{array}{c}\text { Compound } \\
54\end{array}$ & $\begin{array}{c}\text { ChemBL } \\
\text { ID: } \\
\mathbf{4 6 3 2 4 7}\end{array}$ & KPT-185 \\
\hline \multirow[t]{2}{*}{ GI Absorption } & High & & & High \\
\hline & & High & High & \\
\hline \multirow[t]{2}{*}{ BBB Permeant } & No & & & Yes \\
\hline & & No & No & \\
\hline \multirow[t]{2}{*}{ Pgp substrate } & No & & & No \\
\hline & & Yes & Yes & \\
\hline \multirow[t]{2}{*}{ CYP1A2 Inhibitor } & No & & & Yes \\
\hline & & No & No & \\
\hline \multirow[t]{2}{*}{ CYP2C19 inhibitor } & No & & & Yes \\
\hline & & No & No & \\
\hline \multirow[t]{2}{*}{ CYP2C9 inhibitor } & No & & & Yes \\
\hline & & No & No & \\
\hline \multirow[t]{2}{*}{ CYP2D6 inhibitor } & No & & & No \\
\hline & & No & Yes & \\
\hline \multirow[t]{2}{*}{ CYP3A4 inhibitor } & No & & & No \\
\hline & & No & No & \\
\hline
\end{tabular}

Table 5: Druglikeness and Lead-likeness Profile of Hit Compounds

\begin{tabular}{ccccc}
\hline $\begin{array}{c}\text { Compound ID } \\
\text { Property }\end{array}$ & Taxifolin & Compound 54 & $\begin{array}{c}\text { ChemBL ID: } \\
\mathbf{4 6 3 2 4 7}\end{array}$ & KPT-185 \\
\hline $\begin{array}{c}\text { Lipinski's } \\
\text { Violation }\end{array}$ & No & No & No & No \\
\hline $\begin{array}{c}\text { Ghose's } \\
\text { Violation }\end{array}$ & No & No & No & No \\
\hline $\begin{array}{c}\text { Veber's } \\
\text { Violation }\end{array}$ & No & No & No & No \\
\hline Egan's Violation & No & $\begin{array}{c}\text { Yes; } 1 \\
\text { violation: } \\
\text { TPSA>131.6A }\end{array}$ & No & No \\
\hline $\begin{array}{c}\text { Muegge's } \\
\text { Violation }\end{array}$ & No & No & No & No \\
\hline
\end{tabular}




\begin{tabular}{ccccc}
\hline Lead-likeness & Yes & $\begin{array}{c}\text { No }(1 \text { violation; } \\
\text { MW }>350)\end{array}$ & $\begin{array}{c}\text { No (1 violation; MW } \\
>350)\end{array}$ & $\begin{array}{c}\text { No (1 violation; } \\
\text { MW > 350) }\end{array}$ \\
\hline $\begin{array}{c}\text { Bioavailability } \\
\text { Score }\end{array}$ & 0.55 & 0.55 & 0.55 & 0.55 \\
\hline
\end{tabular}

Table 6: Physicochemical, Toxicity, Promiscuity and Synthetic Accessibility Profile of Hit Compounds

\begin{tabular}{ccccc}
\hline $\begin{array}{c}\text { Compound ID } \\
\text { /Property }\end{array}$ & Taxifolin & $\begin{array}{c}\text { Compound } \\
\mathbf{5 4}\end{array}$ & $\begin{array}{c}\text { ChemBL ID: } \\
\mathbf{4 6 3 2 4 7}\end{array}$ & KPT-185 \\
\hline PAINS Alert & 1 alert & 1 alert & Nil & Nil \\
\hline $\begin{array}{c}\text { Number of } \\
\text { Hydrogen } \\
\text { Bond } \\
\text { Acceptors }\end{array}$ & 7 & 7 & 6 & 6 \\
\hline $\begin{array}{c}\text { Number of } \\
\text { Hydrogen } \\
\text { Bond Donors }\end{array}$ & 5 & 5 & 4 & 0 \\
\hline $\begin{array}{c}\text { Number of } \\
\text { Rotatable } \\
\text { Bond }\end{array}$ & 1 & 2 & 5 & 7 \\
\hline $\begin{array}{c}\text { Number of } \\
\text { Aromatic Ring }\end{array}$ & 2 & 2 & 2 & 2 \\
\hline Brenk Alert & 1 alert & 1 alert & Nil & 1 alert \\
\hline $\begin{array}{c}\text { Synthetic } \\
\text { Accessibility } \\
\text { Score }\end{array}$ & 3.51 & 4.31 & 4.15 & 3.29 \\
\hline
\end{tabular}

The druglikeness and bioavailability are interdependent features defining the clinical developability of a drug-like entity ${ }^{91}$. The three hit compounds (taxifolin, compound 54, compound with ChemBL ID: 463247) in this study obeys all the current drug-like and oral bioavailability model rules (except compound 54 violating the Egan et al. (2000) rule ${ }^{11}$ by having topological surface area of greater than $131.6 \AA$ (Table 5), therefore revealing them as drug-like compounds with high Caco-2 cell permeability. However, only taxifolin showed predictively high likelihood 
of clinical developability (Table 5) as an effective E571K Exportin-1 inhibitor, as the other hit compounds (compound 54 and compound with ChemBL ID: 463247) as well as KPT-185 showed lead-likeness limited by molecular weight greater than 350 in violation of the proposed model by Teague et al. $(1999)^{52}$.

The pan assay interference (PAINS) filter of the hit compounds in this study (Table 6), a measure of their potential of exhibiting false positive results in high throughput screening ${ }^{92,5}$, reveals both taxifolin and compound 54 as having high tendency of non-specifically reacting with numerous biological targets rather than specifically on the desirable E571K Exportin-1 while the compound with ChemBL ID: 463247, in similarity to KPT-185, displays significantly low tendency of exhibiting PAINS alert (Table 6). The significantly high promiscuity potential of taxifolin and compound 54, unlike compound with ChemBL ID: 463247 and KPT-185 in this study, shows the duo containing catechol substructure as potential non-selective bioactive response which can therefore restrict their lead-likeness potential as putative E571K Exportin-1 inhibitor for chemotherapy.

The more stringent Brenk model of lead-like compound selection characterized any compound as medicinal that possess both hydrogen bond donor and hydrogen bond acceptor respectively of less than 4 and 7, number of heavy atoms between 10 and 27, ClogP: Clog D ratio of zero to four, limited complexity (definable by less than eight rotatable bonds, less than five ring systems, greater than or equal to two constituted fused ring systems) with the exclusion of reactive and unfavourable groups such as nitros, sulfates, phosphates, 2-halopyridines, and thiols ${ }^{3}$. The violation of Brenk rule by both taxifolin and compound 54 (similar to KPT-185) is as a result of the duo having the cut-off number of 7 hydrogen bond acceptor, more than 4 hydrogen bond donors, as well as containing the reactive catechol as a substructure that characteristically pose 
limitations on their safety profile while that of KPT-185 is as a result of possessing the highly reactive non-ring Michael acceptor group that may have contributed to its associated in vivo side effects.

The synthetic accessibility score of this study hits (Table 6), based on the primary assumption of positive association between ease of synthesis of compounds and their constituted amount of frequently obtainable chemical moieties ${ }^{5}$, reveals easy synthesis of their multiple analogues at an average score of 3.99 (comparably with 3.29 of KPT-185) in which taxifolin and compound with ChemBL ID:463247 being the easiest and most difficult respectively to synthesize on a scale of 1 (easy to synthesize) to 10 (very difficult to synthesize).

\subsection{De novo Generation of Lead Compound Derivatives}

The lead-likeness of taxifolin, among the three hit compounds, in this study (Table 5) presents it as a putative drug-like E571K Exportin-1 inhibitor with high likelihood of qualifying for clinical evaluation and development. Its potential efficacy, however, is limited by its promiscuity tendency in high throughput screening which is a precursor to off-target binding, as well as its violation of Brenk rule of lead-likeness selection due to its constituted catechol substructure. Therefore, exploring the possible chemical space that can be generated from random mutable combination of the compound fragments (based on similar flexophore and dissimilar skelsphere descriptors to that of taxifolin as the parent compound ${ }^{48}$ may presents viable approach toward discovery of its better analogue (s) with the most promising property profile as lead-like E571K Exportin-1 inhibitors.

A nature-mimicking evolutionary approach of randomly mutating the taxifolin structure based on skelsphere similarity (through single atom replacements, atom insertions, changes in bond order, ring aromatization, substituents migration etc. with the exclusion of high ring strains-producing 
mutations) and allowing the 8 best fit child compounds to survive per generation for 50 generations resulted in the generation of 452 novel compounds (having fitness score and skelsphere similarity range of 0.78-1) from which 20 non-toxic, drug-like compounds (molecular weight: 301.3-344.36; skelsphere similarity: 0.80; TPSA: 86.99-124.29; druglikeness score: 0.65-2.88) were obtained following prefiltering based on the procedure and criteria stated in section 2.2.

We evaluated and filtered the resultant 20 novel drug-like taxifolin derivatives based on pan assay interference (PAINS) potential and lead-likeness selection criteria of Brenk et al. $(2008)^{3}$ in this study and obtained five non-toxic, drug-like novel analogues (Table 7; Figure 4) between generation 24 and 43, having aromatic ring and rotatable bond respectively of 2 and 1 each, molecular flexibility score of 0.20-0.27, molecular weight of 303.27-320.73 (Table 9), TPSA of 86.99-120.11, as well as druglikeness score of 0.70-0.77 (Table 7).

Table 7: Simplified Molecular Input Line Entry System Representation of Taxifolin Derivatives with No Brenk and PAINS Alert

\begin{tabular}{ccccc}
\hline $\begin{array}{c}\text { S/N } \\
\text { Compound } \\
\text { Name }\end{array}$ & Generation & SMILES & Druglikeness \\
\hline $\mathbf{1}$ & $\begin{array}{c}\text { Compound } \\
\mathbf{2 2 0}\end{array}$ & $\mathbf{2 4}$ & $\mathrm{Oc} 1 \mathrm{cc} 2 \mathrm{O}[\mathrm{C} @ \mathrm{H}](\mathrm{c} 3 \mathrm{ncc}(\mathrm{c}(\mathrm{c} 3) \mathrm{O}) \mathrm{O})[\mathrm{C} @ @ \mathrm{H}](\mathrm{C}(=\mathrm{O}) \mathrm{c} 2 \mathrm{c}(\mathrm{c} 1) \mathrm{O}) \mathrm{C}$ & 0.77 \\
\hline $\mathbf{2}$ & $\begin{array}{c}\text { Compound } \\
\mathbf{2 3 5}\end{array}$ & $\mathbf{2 6}$ & $\mathrm{Oc} 1 \mathrm{cc} 2 \mathrm{O}[\mathrm{C} @ \mathrm{H}](\mathrm{c} 3 \mathrm{ccc}(\mathrm{c}(\mathrm{c} 3) \mathrm{O}) \mathrm{Cl})[\mathrm{C} @ \mathrm{H}](\mathrm{C}(=\mathrm{O}) \mathrm{c} 2 \mathrm{c}(\mathrm{c} 1) \mathrm{O}) \mathrm{C}$ & 0.70 \\
\hline $\mathbf{4}$ & $\begin{array}{c}\text { Compound } \\
\mathbf{2 5 0}\end{array}$ & $\mathbf{2 8}$ & $\mathrm{Oc} 1 \mathrm{cc} 2 \mathrm{O}[\mathrm{C} @ \mathrm{H}](\mathrm{c} 3 \mathrm{cnc}(\mathrm{c}(\mathrm{c} 3) \mathrm{O}) \mathrm{O})[\mathrm{C} @ \mathrm{H}](\mathrm{C}(=\mathrm{O}) \mathrm{c} 2 \mathrm{c}(\mathrm{c} 1) \mathrm{O}) \mathrm{C}$ & 0.77 \\
\hline $\mathbf{5}$ & $\begin{array}{c}\text { Compound } \\
\mathbf{2 9 4}\end{array}$ & $\mathbf{3 3}$ & $\mathrm{Oc} 1 \mathrm{cc} 2 \mathrm{O}[\mathrm{C} @ \mathrm{H}](\mathrm{c} 3 \mathrm{ncc}(\mathrm{c}(\mathrm{c} 3) \mathrm{O}) \mathrm{O})[\mathrm{C} @ \mathrm{H}](\mathrm{C}(=\mathrm{O}) \mathrm{c} 2 \mathrm{c}(\mathrm{c} 1) \mathrm{O}) \mathrm{C}$ & 0.77 \\
\hline $\mathbf{6}$ & $\begin{array}{c}\text { Compound } \\
\mathbf{3 7 9}\end{array}$ & $\mathbf{4 3}$ & $\mathrm{Oc} 1 \mathrm{cc} 2 \mathrm{O}[\mathrm{C} @ @ \mathrm{H}](\mathrm{c} 3 \mathrm{ncc}(\mathrm{c}(\mathrm{c} 3) \mathrm{O}) \mathrm{O})[\mathrm{C} @ @ \mathrm{H}](\mathrm{C}(=\mathrm{O}) \mathrm{c} 2 \mathrm{c}(\mathrm{c} 1) \mathrm{O}) \mathrm{C}$ & 0.77 \\
& & &
\end{tabular}


(A)<smiles>C[C@H]1C(=O)c2c(O)cc(O)cc2O[C@H]1c1cc(O)c(O)cn1</smiles>

(D)<smiles>C[C@H]1C(=O)c2c(O)cc(O)cc2O[C@H]1c1cc(O)c(O)cn1</smiles>

(B)<smiles>C[C@H]1C(=O)c2c(O)cc(O)cc2O[C@H]1c1ccc(Cl)c(O)c1</smiles><smiles>C[C@H]1C(=O)c2c(O)cc(O)cc2O[C@H]1c1cc(O)c(O)cn1</smiles>

Figure 4: Structural Representation of Taxifolin Derivatives with No Brenk and PAINS Alert (A) Compound 220 of Generation 24 (B) Compound 235 of Generation 26 (C) Compound 250 of Generation 28 (D) Compound 294 of Generation 33 (D) Compound 374 of Generation 43

\subsection{Physicochemical, Druglikeness, and Toxicity Properties of Taxifolin Derivatives with No Brenk and PAINS Alert}

The resultant five taxifolin analogues with no Brenk and PAINS alert in this study shows high gastrointestinal permeability but possess property, unlike their parent compound (Table 4), which rendered them as substrate for P-glycoprotein receptor (Table 8). This, given the fact that they are non-blood brain barrier- permeable (Table 10), may contributes toward their reduced potential of inducing any side effects associated with the neurological system while aiding in preventing accumulation of the drug entities, via excretion, en route the action site. Also, the analogues, 
similar to the parent taxifolin compound (Table 4), display non-inhibition tendency toward the various studied cytochrome P450 isoforms, except compound 235 of generation 26 (Table 8).

The bioavailability score of the analogue compounds with no Brenk and PAINS alert (0.55), in similarity to that of the taxifolin parent compound, also present them as orally bioavailable compounds (Table 9) while obeying the various conventional oral bioavailability and druglikeness model rules.

Furthermore, the lead-likeness evaluation of these no-Brenk-and-PAINS-alert taxifolin analogues shows them as non-toxic compounds with high tendency of clinical developability (Table 10) while their range of synthetic accessibility score (3.48-3.59) presents them as easy to synthesize (comparably with that of their parent compound) for further preclinical and clinical evaluation. 
Table 8: Absorption and Metabolic Profile of Taxifolin Derivatives with No Brenk and PAINS Alert

\begin{tabular}{cccccc}
\hline $\begin{array}{c}\text { Compound ID } \\
\text { /Property }\end{array}$ & $\mathbf{2 2 0}$ & $\mathbf{2 3 5}$ & $\mathbf{2 5 0}$ & $\mathbf{2 9 4}$ & $\mathbf{3 7 9}$ \\
\hline $\begin{array}{c}\text { Generation } \\
\text { GI Absorption }\end{array}$ & $\mathbf{2 4}$ & $\mathbf{2 6}$ & $\mathbf{2 8}$ & $\mathbf{3 3}$ & $\mathbf{4 3}$ \\
\hline BBB & High & High & High & High \\
\hline Pgp substrate & Yes & Yes & Yes & Yes & Yes \\
\hline $\begin{array}{l}\text { CYP1A2 } \\
\text { Inhibitor }\end{array}$ & No & No & No & No & No \\
\hline $\begin{array}{l}\text { CYP2C19 } \\
\text { Inhibitor }\end{array}$ & No & Yes & No & No & No \\
\hline $\begin{array}{l}\text { CYP2C9 } \\
\text { inhibitor }\end{array}$ & No & No & No & No & No \\
\hline $\begin{array}{l}\text { CYP2D6 } \\
\text { Inhibitor }\end{array}$ & No & Yes & No & No & No \\
\hline $\begin{array}{l}\text { CYP3A4 } \\
\text { Inhibitor }\end{array}$ & No & Yes & No & No & No \\
\hline
\end{tabular}

Table 9: Oral Bioavailability Profile of Taxifolin Derivatives with No Brenk and PAINS Alert

\begin{tabular}{cccccc}
\hline $\begin{array}{c}\text { Compound ID } \\
\text { Property }\end{array}$ & $\mathbf{2 2 0}$ & $\mathbf{2 3 5}$ & $\mathbf{2 5 0}$ & $\mathbf{2 9 4}$ & $\mathbf{3 7 9}$ \\
\hline Generation & $\mathbf{2 4}$ & $\mathbf{2 6}$ & $\mathbf{2 8}$ & $\mathbf{3 3}$ & $\mathbf{4 3}$ \\
\hline $\begin{array}{c}\text { Molecular } \\
\text { Weight }\end{array}$ & 303.27 & 320.72 & 303.27 & 303.27 & 303.27 \\
\hline $\begin{array}{c}\text { Lipinski's } \\
\text { Violation }\end{array}$ & No & No & No & No & No \\
\hline $\begin{array}{c}\text { Ghose's } \\
\text { Violation }\end{array}$ & No & No & No & No & No \\
\hline $\begin{array}{c}\text { Veber's } \\
\text { Violation }\end{array}$ & No & No & No & No & No \\
\hline $\begin{array}{c}\text { Egan's } \\
\text { Violation }\end{array}$ & No & No & No & No & No \\
\hline $\begin{array}{c}\text { Muegge's } \\
\text { Violation }\end{array}$ & No & No & No & No & No \\
\hline CLogP & 1.1324 & 3.031 & 1.4298 & 1.1324 & 1.1324 \\
\hline
\end{tabular}




\begin{tabular}{cccccc}
$\begin{array}{c}\text { Bioavailability } \\
\text { Score }\end{array}$ & 0.55 & 0.55 & 0.55 & 0.55 & 0.55 \\
\hline
\end{tabular}

Table 10: Toxicity, Lead-likeness, Promiscuity and Synthetic Accessibility Profile of Taxifolin Derivatives with No Brenk and PAINS Alert

\begin{tabular}{cccccc}
\hline $\begin{array}{c}\text { Compound } \\
\text { ID } / \text { Property }\end{array}$ & $\mathbf{2 2 0}$ & $\mathbf{2 3 5}$ & $\mathbf{2 5 0}$ & $\mathbf{2 9 4}$ & $\mathbf{3 7 9}$ \\
\hline Generation & $\mathbf{2 4}$ & $\mathbf{2 6}$ & $\mathbf{2 8}$ & $\mathbf{3 3}$ & $\mathbf{4 3}$ \\
\hline PAINS Alert & Nil & Nil & Nil & Nil & Nil \\
\hline $\begin{array}{c}\text { BRENK } \\
\text { Alert }\end{array}$ & Nil & Nil & Nil & Nil & Nil \\
\hline $\begin{array}{c}\text { Lead- } \\
\text { likeness }\end{array}$ & Yes & Yes & Yes & Yes & Yes \\
$\begin{array}{c}\text { Synthetic } \\
\text { Accessibility } \\
\text { Score }\end{array}$ & 3.59 & 3.48 & 3.53 & 3.59 & 3.59 \\
\hline
\end{tabular}

\subsection{Bioactivity Profile of Taxifolin Derivatives with No Brenk and PAINS Alert}

Evaluating the bioactivity probability of the obtained lead-like taxifolin derivatives with no Brenk and PAINS alert in this study (Table 11) characteristically reveals the compounds as highly active ligand of the nuclear receptor such as E571K Exportin-1, when compared with that of KPT-185. Both compound 235 and 250 of generation 26 and 28 respectively exhibits the relatively highest bioactivity against nuclear receptors (Table 11), when compared with KPT-185. It is also noteworthy that although these taxifolin analogues tend to also exhibit moderate activity in modulating ion channel, inhibiting kinase and protease enzymes, as well as actively inhibiting Gprotein coupled receptors and enzymes; their lack of PAINS alert, unlike the parent taxifolin, presents the plausibility of restrictively advancing their bioactivity specifically against the nuclear E571K Exportin-1. 
Table 11: Bioactivity Score of Taxifolin Derivatives with No Brenk and PAINS Alert

\begin{tabular}{ccccccc}
\hline $\begin{array}{c}\text { Compound } \\
\text { ID } \\
\text { /Targetability }\end{array}$ & $\mathbf{2 2 0}$ & $\mathbf{2 3 5}$ & $\mathbf{2 5 0}$ & $\mathbf{2 9 4}$ & $\mathbf{3 7 9}$ & KPT-185 \\
\hline $\begin{array}{c}\text { GPCR } \\
\text { Ligand }\end{array}$ & 0.15 & 0.10 & 0.20 & 0.15 & 0.15 & 0.11 \\
\hline $\begin{array}{c}\text { Ion Channel } \\
\text { Modulator }\end{array}$ & -0.06 & -0.13 & 0.19 & -0.09 & -0.06 & -0.07 \\
\hline $\begin{array}{c}\text { Kinase } \\
\text { Inhibitor }\end{array}$ & 0.11 & -0.12 & -0.01 & 0.11 & 0.11 & -0.08 \\
\hline $\begin{array}{c}\text { Nuclear } \\
\text { Receptor } \\
\text { Ligand }\end{array}$ & 0.38 & 0.58 & 0.57 & 0.38 & 0.38 & -0.17 \\
\hline $\begin{array}{c}\text { Protease } \\
\text { Inhibitor }\end{array}$ & -0.01 & -0.18 & -0.10 & -0.01 & -0.01 & -0.19 \\
\hline $\begin{array}{c}\text { Enzyme } \\
\text { Inhibitor }\end{array}$ & 0.33 & 0.15 & 0.48 & 0.33 & 0.33 & 0.02 \\
\hline
\end{tabular}

\subsection{Binding Affinities of Taxifolin Derivatives with No Brenk and PAINS Alert}

Comparative evaluation of binding affinity potential of the lead-like non-promiscuous taxifolin analogues as putative E571K Exportin-1 inhibitors against the parent taxifolin compound and KPT-185 in this study (Figure 5) reveals compound 235 of generation 26 as having relatively higher binding affinity $(-5.3 \mathrm{kcal} / \mathrm{mol})$ than both taxifolin $(-5 \mathrm{kcal} / \mathrm{mol})$ and KPT-185 $(-5 \mathrm{kcal} / \mathrm{mol})$ while both compound 220 and compound 379 respectively of generation 24 and 43 shows comparatively equivalent binding affinity with the parent compound and KPT-185 (Figure 5). It is also noteworthy that the characteristic display of highest binding affinity (Figure 5) and highest bioactivity tendency against nuclear receptors (Table 11) by compound 235 of generation 26 in this study, coupled with its lack of Brenk and PAINS alert, may advance the potential of the 
taxifolin analogue as the most effective, potent, and safe E571K Exportin-1 inhibitor in KRASmutant lung adenocarcinoma therapy.

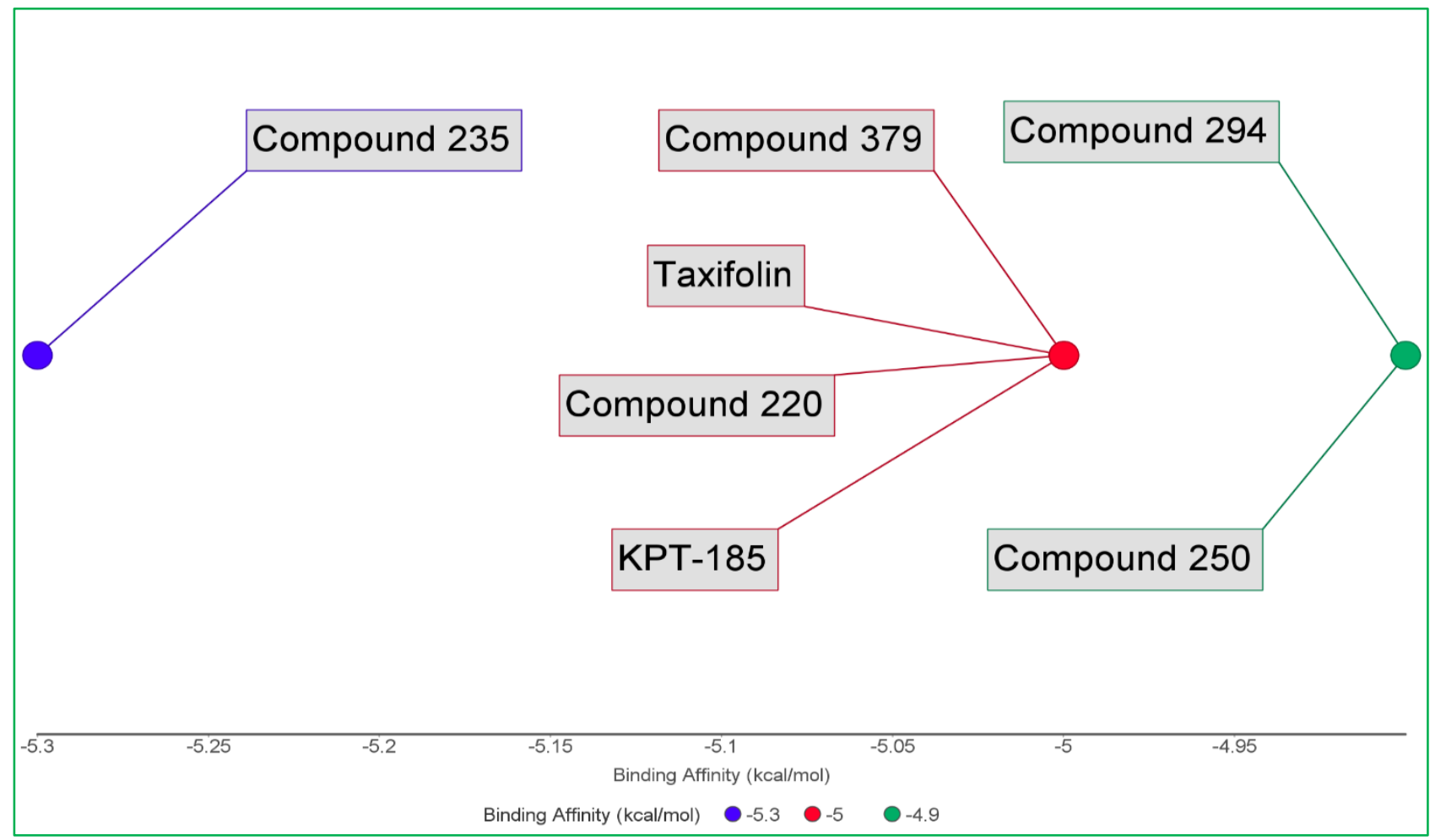

Figure 5: Comparative Docking Scores of Taxifolin and its Derivatives with No BRENK and PAINS Alert 


\subsection{Interaction Between E571K Exportin-1 and Taxifolin Derivatives with No Brenk} and PAINS Alert

(A)
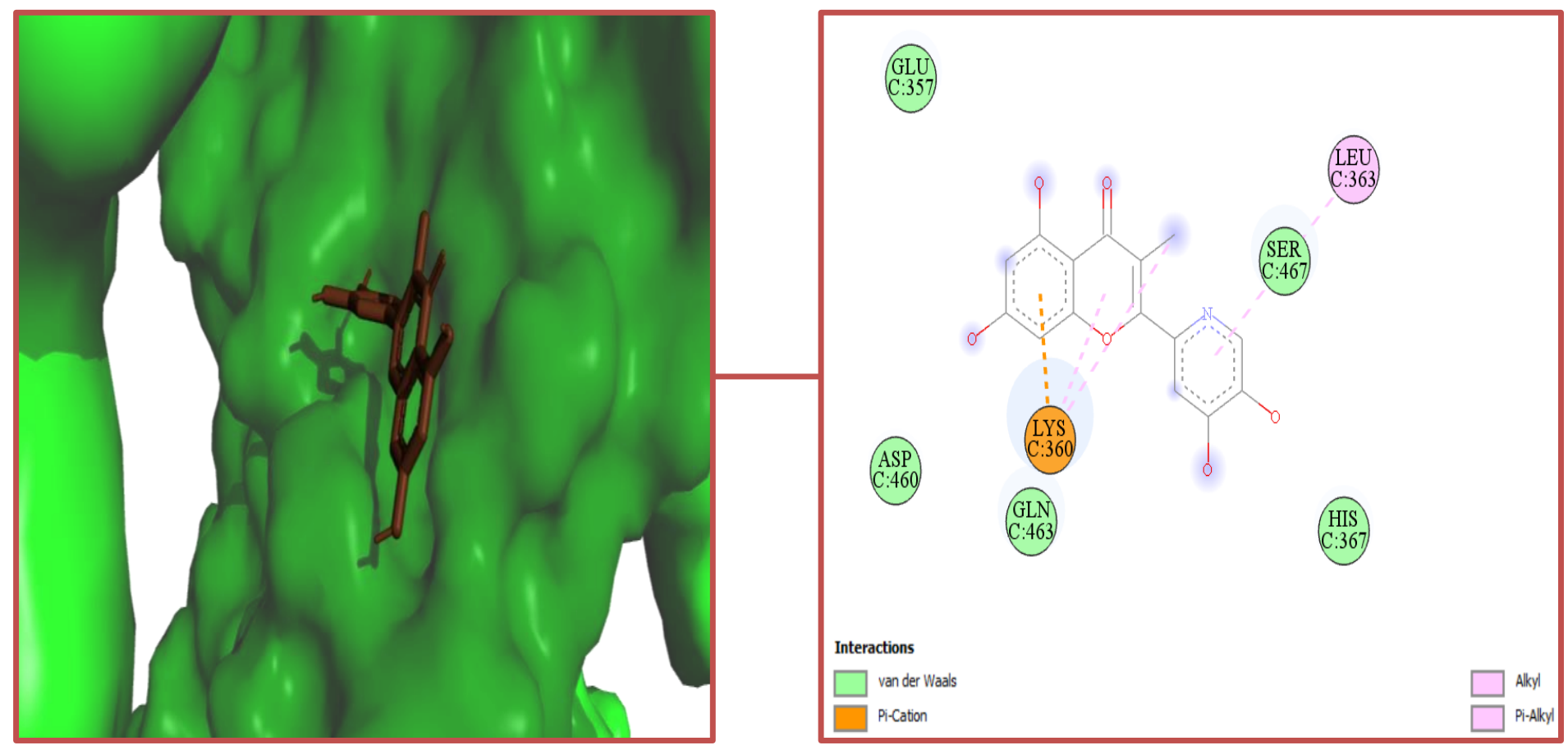

(B)
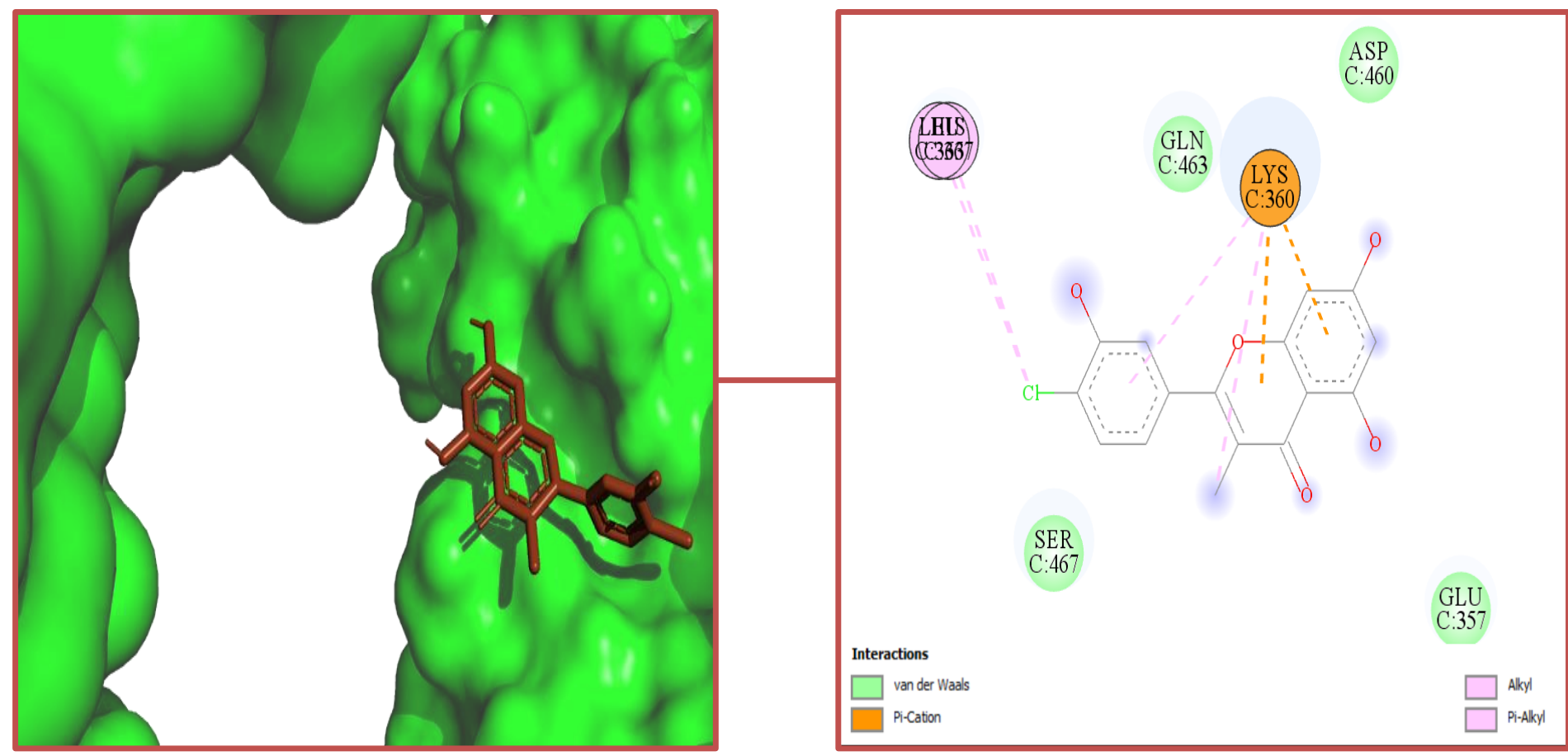
(C)

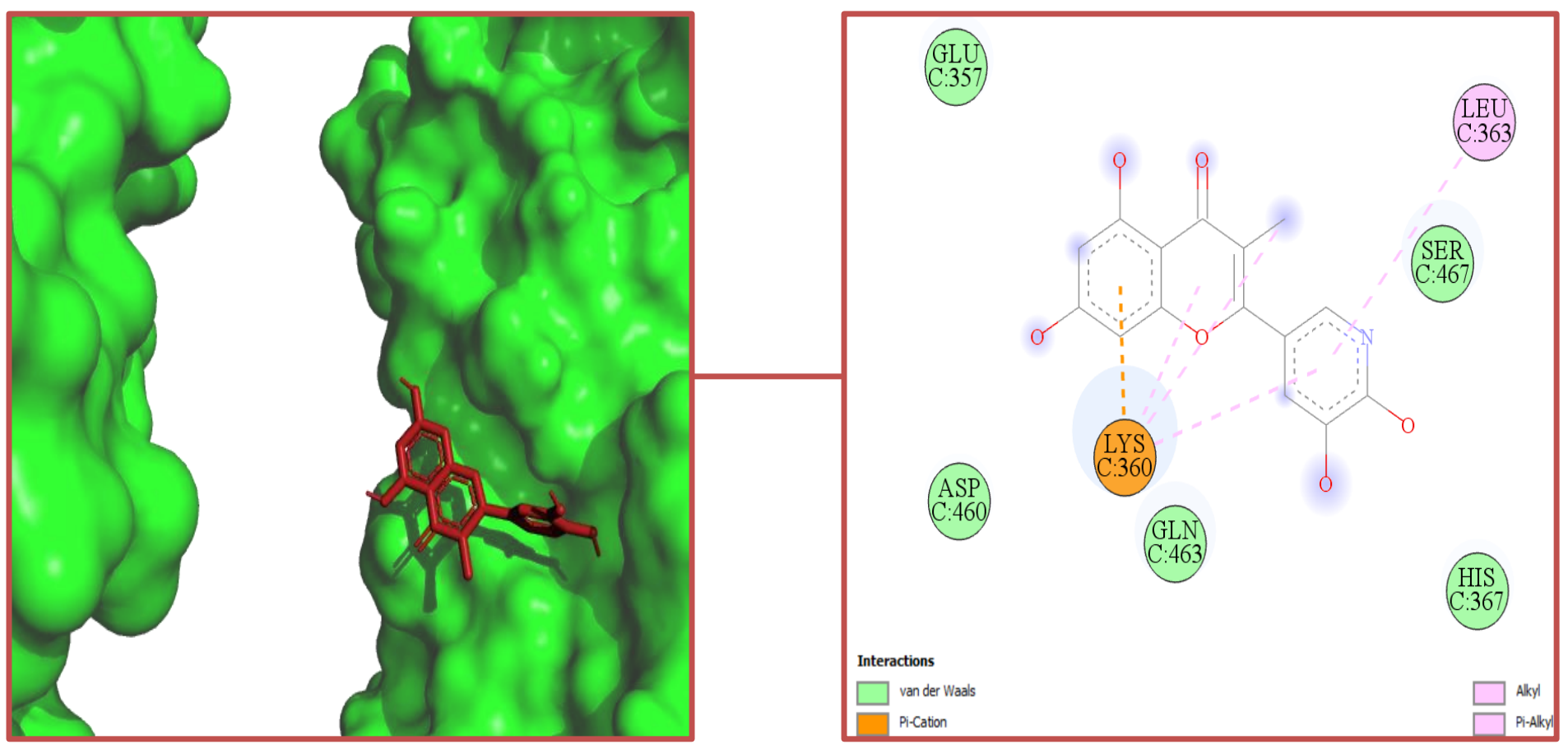

(D)

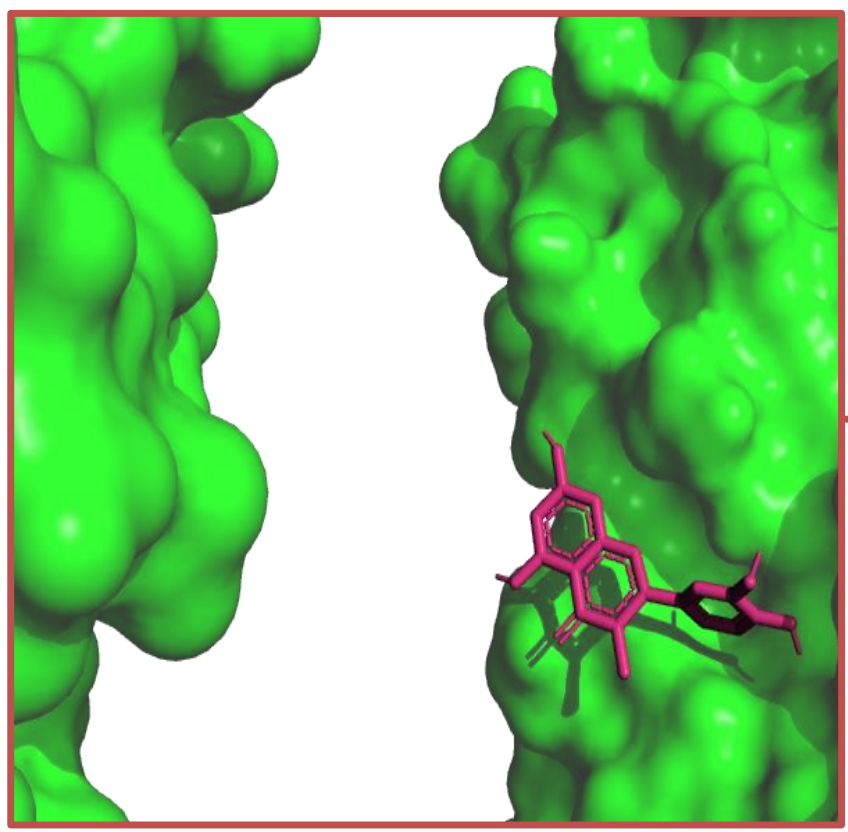

GLU

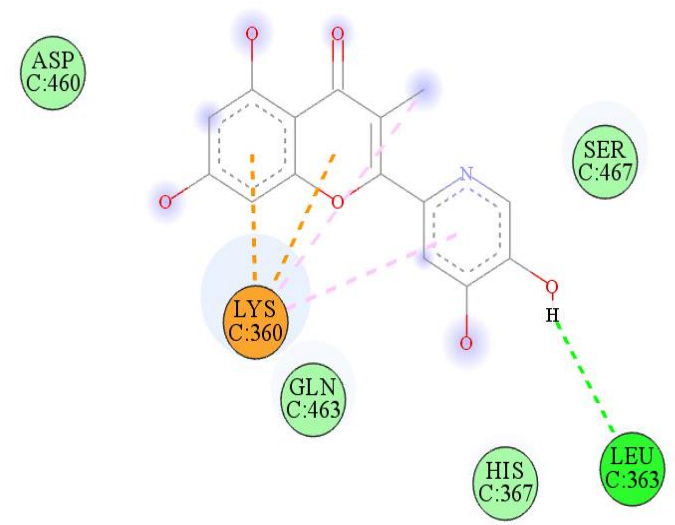

Interactions

$\square$ van der Waals

Conventional Hydrogen Bond

Pi-Cation 
(E)

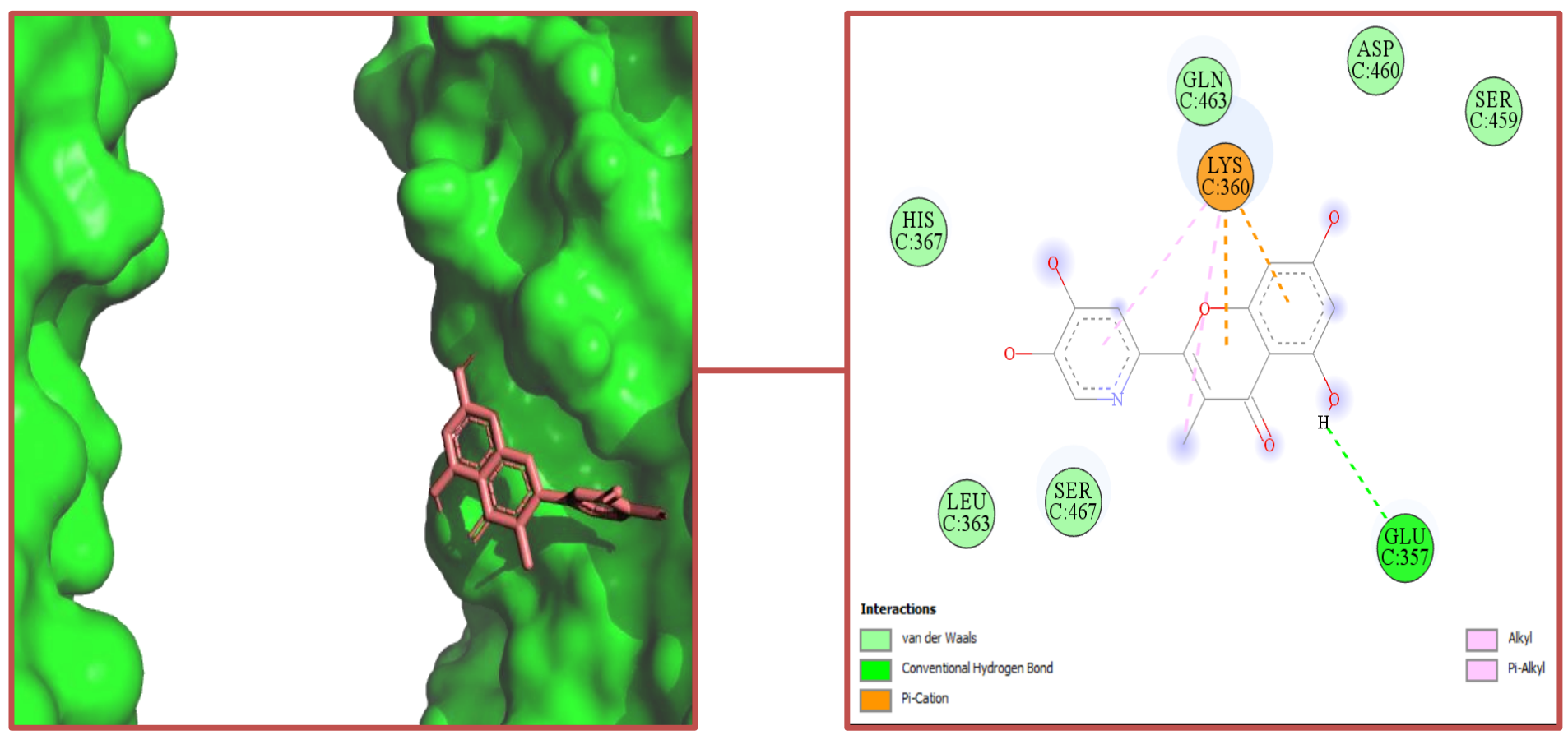

Figure 6: Representation of Ligand-Target Interaction. (A) Interaction between Compound 220 and E571K Exportin-1 (B) Interaction between Compound 235 and E571K Exportin-1 (C) Interaction between Compound 250 and E571K Exportin-1 (D) Interaction between Compound 294 and E571K Exportin-1 (E) Interaction between Compound 379 and E571K Exportin-1

Examining the interaction between the non-promiscuous lead-like taxifolin analogues with the binding site of E571K Exportin-1 in this study reveals formation of electrostatic Pi-cation dipole moment (Figure 6) with the active lysine residue 360; a mechanism earlier stated (section 3.4) as having plausibly significant contributory role in E571K Exportin-1 inhibition. This is in addition to compound 220 (Figure 6A), 235 (Figure 6B), and 250 (Figure 6C) of generation 24, 26, and 28 respectively forming Pi-alkyl bond with Leu 363 of E571K Exportin-1 active site; a feature which is notably absent in their parent compound (Figure 3A). Compound 235 of generation 26, however, formed additional Pi-alkyl interaction with the active histidine residue 367 (Figure 6B) that may have contributed toward its relatively higher binding affinity (Figure 5) and led credence to our 
earlier deduction (section 3.9) that the compound, among the lead-like non-promiscuous taxifolin analogues in this study, tends toward exhibiting the highest E571K Exportin-1 inhibition for KRAS-mutant lung adenocarcinoma therapy.

\subsection{Conclusion and Future Perspectives}

The E571K mutant of exportin-1 plays pointed role in the recurrently poor prognosis of KRASmutant lung adenocarcinoma through advancement of drug resistance. The development of its potent and clinically acceptable antagonist, therefore, is a provably effective strategy in the treatment of this highly untreatable condition. We discovered novel analogues of taxifolin (obtained from Juglans mandshurica) as putatively non-promiscuous and clinically developable exportin-1 inhibitors with better pharmacokinetic properties than the clinically evaluated SINE KPT-185 compound (as the standard) in this study. This study, therefore, has provided evidence in support of assaying for effectiveness, potency and safety metrics of these taxifolin derivatives as E571K Exportin-1 antagonists in both pre-clinical and clinical studies involving KRAS-mutant lung adenocarcinoma chemotherapy.

\section{CONFLICT OF INTEREST}

The authors declare no conflict of interest.

\section{ABBREVIATION}

KRAS: Kirsten Rat Sarcoma 2 Viral Oncogene Homolog. 


\section{References}

1. Andrews KA, Wesche D, McCarthy J, Möhrle JJ, Tarning J, Phillips L, et al. Modelinformed drug development for malaria therapeutics. Annual Review of Pharmacology and Toxicology. 2018; 58: 567-582 (Doi: 10.1146/ annurev-pharmtox-010715-103429).

2. Blum ARC, Blesa M, Sampels M. Hybrid metaheuristics: An emerging approach to optimization. Springer-Verlag, Berlin, Heidelberg. 2008.

3. Brenk R, Schipani A, James D, Krasowski A, Gilbert IH, Frearson J, et al. Lessons learnt from assembling screening libraries for drug discovery for neglected diseases. ChemMedChem. 2008; 3(3): 435-444.

4. Coracini JD, de Azevedo WF. Shikimate kinase, a protein target for drug design. Curr. Med Chem. 2014; 21: 592-604.

5. Daina A, Michielin O, Zoete V. SwissADME: a free web tool to evaluate pharmacokinetics, druglikeness and medicinal chemistry friendliness of small molecules. Sci. Rep. 2017; 7: 42717 (Doi: 10.1038/srep42717).

6. de Boer AG, van der Sandt ICJ, Gaillard PJ. The role of drug transporters at the bloodbrain barrier. Annual Review of Pharmacology and Toxicology. 2003; 43: 629-656 (Doi: 10.1146/annurev.pharmtox.43.100901.140204).

7. Dhananjayan K. Molecular Docking Study Characterization of Rare Flavonoids at the NacBinding Site of the First Bromodomain of BRD4 (BRD4 BD1). Journal of Cancer Research. 2015; Article ID 762716: 15 pages (Doi: 10.1155/2015/762716).

8. Dhorajiwala TM, Halder ST, Samant L. Comparative In Silico molecular docking analysis of 1-threonine-3-dehydrogenase, a protein target against African trypanosomiasis using selected phytochemicals. J Appl Biotechnol Rep. 2019; 6(3): 101-108.

9. Di L. The role of drug metabolizing enzymes in clearance. Expert Opin. Drug Metab. Toxicol. 2014; 10: 379-393.

10. Du X, Li Y, Xia YL, Ai SM, Liang J, Sang P, et al. Insights into Protein-Ligand Interactions: Mechanisms, models, and methods. Int. J. Mol. Sci. 2016; 17: 144 (Doi: 10.3390/ijms 17020144).

11. Egan WJ, Merz KM, Baldwin JJ. Prediction of drug absorption using multivariate statistics. J Med Chem. 2000; 43 (21): 3867-3877. 
12. Egieyeh SA, Syce J, Malan SF, Christoffels A. Prioritization of anti-malarial hits from nature: chemo-informatic profiling of natural products with in vitro antiplasmodial activities and currently registered anti-malarial drugs. Malar J. 2016; 15:50 (Doi: 10.1186/s12936-016-1087-y).

13. Ertl P, Schuffenhauer A. Estimation of synthetic accessibility score of drug-like molecules based on molecular complexity and fragment contributions. J. Cheminform. 2009; 1: 8.

14. Etchin J, Sun Q, Kentsis A, et al. Antileukemic activity of nuclear export inhibitors that spare normal hematopoietic cells. Leukemia. 2012; 27: 66.

15. Feher M, Schmidt JM. Property distributions: Differences between drugs, natural products, and molecules from combinatorial chemistry. J Chem Inf Comput Sci. 2003; 43: 218-227.

16. Ferreira BI, Cautain B, Grenho I, Link W. Small Molecule Inhibitors of CRM1. Front. Pharmacol. 2020; 11: 625 (Doi: 10.3389/fphar.2020.00625).

17. Garcia-Santisteban I, Arregi I, Alonso-Marino M, Urbaneja MA, Garcia-Vallejo JJ, Banuelos S, et al. A cellular reporter to evaluate CRM1 nuclear export activity: functional analysis of the cancer-related mutant E571K. Cell. Mol. Life. Sci. (2016); 73: 4685-4699 (Doi: 10.1007/s00018-016-2292-0).

18. Garg M, Kanojia D, Mayakonda A, Ganesan TS, Sadhanandhan B, Suresh S, et al. Selinexor (KPT-330) has antitumor activity against anaplastic thyroid carcinoma in vitro and in vivo, and enhances sensitivity to doxorubicin. Sci. Rep. 2017; 7: 9749.

19. Grant JA, Gallardo MA, Pickup BT. A fast method of molecular shape comparison: A simple application of a Gaussian description of molecular shape. 1996; 17 (14):1653-1666 (Doi:10.1002/(SICI)1096-987X(19961115)17:14<1653::AID-JCC7>3.0.CO;2-K).

20. Haines JD, Herbin O, de la Hera B, Vidaurre OG, Moy GA, Sun Q, Joyce FHY, Albrecht S, Alexandropoulos K, McCauley D, Chook YM, Kuhlmann T, Kidd GJ, Shacham S, Casaccia P. Nuclear export inhibitors avert progression in preclinical models of inflammatory demyelination. Neuroscience. 2015; 12: 11-19 (Doi: 10.1038/nn.3953).

21. Han L, Li W, Narimatsu S, Liu L, Fu H, Okuda H, Koike K. Inhibitory effects of compounds isolated from fruit of Juglans mandshurica on pancreatic lipase. J Nat Med. 2007; 61:184-186 (Doi: 10.1007/s11418-006-0109-4).

22. Hann M, Leach A, Harper G. Molecular complexity and its impact on the probability of finding leads for drug discovery. J Chem Inf Comput Sci. 2001; 41: 856-64. 
23. Heck GS, Pintro VO, Pereira RR, de Avila MB, Levin NMB, de Azevedo WF. Supervised machine learning methods applied to predict ligand-binding affinity. Curr Med Chem. 2017; 24: 2459-2470.

24. Hing ZA, Fung HYJ, Ranganathan P, Mitchell S, El-Gamal D, Woyach JA, Williams K, Goettl VM, Smith J, Yu X, Meng X, Sun Q, Cagatay T, Lehman AM, Lucas DM, Baloglu E, Shacham S, Kauffman MG, Byrd JC, Chook YM, Garzon R, Lapalombella R. Next generation XPO1 inhibitor shows improved efficacy and in vivo tolerability in hematologic malignancies. Leukemia. 2016; 30 (12): 2364-2372 (Doi: 10.1038/leu.2016.136).

25. Hsu KC, Chen YF, Lin SR, Yang JM. iGEMDOCK: a graphical environment of enhancing GEMDOCK using pharmacological interactions and post-screening analysis. BMC Bioinformatics. 2011; 12 (Suppl 1): S33.

26. Huey R, Morris GM, Olson AJ, Goodsell DS. A semi-empirical free energy force field with charge-based desolvation. J Comput Chem. 2007; 28: 1145-1152.

27. Jahanban-Esfahlan A, Ostadrahimi A, Tabibiazar M, Amarowicz R. A Comprehensive Review on the chemical constituents and functional Uses of walnut (Juglans spp.) Husk. Int. J. Mol. Sci. 2019; 20: 3920 (Doi:10.3390/ijms20163920).

28. Kima JY, Lee EJ, Ahn Y, Park SJ, Kim SH, Oh SH. A chemical compound from fruit extract of Juglans mandshurica inhibits melanogenesis through p-ERK-associated MITF degradation Phytomedicine. 2019; 57: 57-64.

29. Klebe G, Bohm HJ. Energetic and entropic factors: Determining binding affinity in Protein-Ligand complexes. J. Receptor Signal Transduction Res. 1997; 17: 459-473.

30. Kortagere S, Krasowski MD, Ekins S. The importance of discerning shape in molecular pharmacology. Trends Pharmacol Sci. 2009; 30(3): 138-147 (Doi: 10.1016/j.tips.2008.12.001).

31. Lapalombella R, Sun Q, Williams K, et al. Selective inhibitors of nuclear export show that CRM1/XPO1 is a target in chronic lymphocytic leukemia. Blood. 2012; 120: 4621-4634.

32. Lee KS, Li G, Kim SH, Lee CS, Woo MH, Lee SH, et al. Cytotoxic Diarylheptanoids from the Roots of Juglans mandshurica. J. Nat. Prod. 2002; 65: 1707-1708.

33. Li J, Xu KP, Zou ZX, Zou H, Long HP, Tan LH, et al. Two new compounds from the green peel of Juglans mandshurica. Journal of Asian Natural Products Research. 2017; 23-28 (Doi: 10.1080/10286020.2017.1295228). 
34. Liu L, Li W, Koike K, Zhang S, Nikaido T. New a-Tetralonyl Glucosides from the fruit of Juglans mandshurica. Chem. Pharm. Bull. 2004; 52(5) 566-569.

35. Liu L, Li W, Sasaki T, Asada Y, Koike K. Juglanone, a novel a-tetralonyl derivative with potent antioxidant activity from Juglans mandshurica. J Nat Med. 2010; 64:496-499 (Doi: 10.1007/s11418-010-0435-4).

36. Lou LL, Cheng ZY, Guo R, Yao GD, Song SJ. Alkaloids from Juglans Mandshurica maxim induce distinctive cell death in hepatocellular carcinoma cells. Natural Product Research 2017; 22:2-9 (Doi: 10.1080/14786419.2017.1413571).

37. Lovering, F. Escape from flatland 2: complexity and promiscuity. MedChemComm. 2013; 4: 515-519.

38. Lovering, F. et al. Escape from flatland: increasing saturation as an approach to improving clinical success. J. Med. Chem. 2009; 52: 6752-6756.

39. Me'ndez-Lucio OQ, Medina-Franco JL. The many roles of molecular complexity in drug discovery. Drug Discovery Today. 2016; 11 (12): 15-18.

40. Meng XY, Zhang HX, Mezei M, Cui M. Molecular Docking: a powerful approach for structure-based drug discovery. Curr Comput Aided Drug Des. 2011; 7(2): 146-157. (PMCID: PMC3151162).

41. Min BS, Lee HK, Lee SM, Kim YH, Bae KH, Otake T, et al. Anti-Human Immunodeficiency Virus-Type 1 activity of constituents from Juglans mandshurica. Arch Pharm Res. 2002; 25 (4): 441-445.

42. Mishra S, Dahima R. In-vitro ADME studies of TUG-891, a GPR-120 inhibitor using Swiss ADME predictor. Journal of Drug Delivery and Therapeutics. 2019; 9(2-s): 366369 (Doi: 10.22270/jddt.v9i2-s.2710).

43. Mobley DL, Dill KA. Binding of small-molecule ligands to proteins: "What You See" Is Not Always "What You Get". Structure. 2009; 17(4): 489-498 (Doi: 10.1016/j.str.2009.02.010).

44. Nocedal J, Wright SJ. Numerical optimization. Springer Verlag: Berlin. 1999 (Springer Series in Operations Research).

45. Park SJ, Kim N, Yoo G, Kim SN, Kwon HJ, Jung K, et al. Phenolics and neolignans isolated from the fruits of Juglans mandshurica Maxim. and their effects on lipolysis in adipocytes. Phytochemistry. 2017; 137: 87-93. 
46. Peach ML, Cachau RE, Nicklaus MC. Conformational energy range of ligands in protein crystal structures: the difficult quest for accurate understanding. J Mol Recognit. 2017; 30(8): 26-29 (Doi: 10.1002/jmr.2618).

47. Sánchez-Linares, I, Pérez-Sánchez, H, Cecilia, JM, Garcia JM. High throughput parallel blind virtual screening using BINDSURF. BMC Bioinformatics. 2012; 13: S13.

48. Sander, T, Freyss J, von Korff M, Rufener C. DataWarrior: An open-source program for chemistry aware data visualization and analysis. J. Chem. Inf. Model. 2014; 1-13 (Doi: 10.1021/ci500588j).

49. Santos MAB, Oliveira LFS, Figueiredo AF, Gil FS, Farias MS, Bitencourt HR, et al. A Bioavailability Score. J. Med. Chem. 2005; 48: 3164-3170.

50. Sauer WHB, Schwarz MK. Molecular shape diversity of combinatorial libraries: a prerequisite for broad bioactivity. J. Chem. Inf. Comput. Sci. 2003; 43: 987-1003.

51. Sun H, Hattori N, Chien W, Sun Q, Sudo M, E-Ling GL, Ding L, Lim SL, Shacham S, Kadman M, Nakamaki T, Koeffler HP. KPT-330 has antitumor activity against non-small cell lung cancer. Br. J. Cancer. 2014; 111: 281-294.

52. Teague SJ, Davis AM, Leeson PD, Oprea T. The design of lead-like combinatorial libraries. Angew Chem Int Ed Engl. 1999; 38(24): 3743- 3748.

53. The AACR Project GENIE Consortium. AACR Project GENIE: Powering Precision Medicine Through an International Consortium. Cancer Discovery 2017; 7 (8): 818-831 (Dataset version 8).

54. Trott O, Olson AJ. AutoDock Vina: Improving the speed and accuracy of docking with a new scoring function, efficient optimization, and multithreading. J. Comput. Chem. 2010; 31: 455-461 (Doi: 10.1002/jcc.21334).

55. Wang AD, Xie CJ, Zhang YQ, Li MC, Wang X, Liu JY, et al. $\alpha$-Tetralonyl glucosides from the green walnut husks of Juglans mandshurica and their antiproliferative effects. Planta Med 2019; ISSN 0032-0943 (Doi: 10.1055/a-0832-2328).

56. Wang Q, Pang YP. Preference of small molecules for local minimum conformations when binding to proteins. PLoS ONE. 2007; 2(9): e820 (Doi: 10.1371/journal.pone.0000820).

57. Wang TM, Fu Y, Yu WJ, Chen C, Di X, Zhang H, et al. Identification of polar constituents in the decoction of Juglans mandshurica and in the medicated egg prepared with the 
decoction by HPLC-Q-TOF MS2. Molecules. 2017; 22 : 1452 (Doi:10.3390/molecules22091452).

58. Wolf CR, Smith G, Smith RL. Pharmacogenetics. British Medical Journal. 2000.

59. Yang JM, Chen CC. GEMDOCK: a generic evolutionary method for molecular docking. Proteins. 2004; 55: 288-304 (Doi: 10.1002/prot.20035).

60. Yao DL, Zhang CH, Li R, Luo J, Jin M, Piao JH, et al. Two new conjugated ketonic fatty acids from the stem bark of Juglans mandshurica. Chinese Journal of Natural Medicines 2015; 13 (4): 0299-0302.

61. Yao DL, Zhang CH, Luo J, Jin M, Zheng MS, Cui JM, et al. Chemical constituents from the leaves of Juglans mandshurica. Arch. Pharm. Res. 2014; 712-749 (Doi: 10.1007/s12272-014-0398-1).

62. Zhang XN, Bai M, Cheng ZY, Yu ZG, Huang XX. Cytotoxic lignans from the barks of Juglans mandshurica. Journal of Asian Natural Products Research 2017; 12: 15-18 (Doi: 10.1080/10286020.2017.1374256).

63. Zhao H, Caflisch A. Discovery of ZAP70 inhibitors by high-throughput docking into a conformation of its kinase domain generated by molecular dynamics," Bioorganic \& Medicinal Chemistry Letters. 2013; 23 (20): 5721-5726.

64. Zhao H, Huang D. Hydrogen bonding penalty upon ligand binding. PLoS ONE. 2011; 6 (6): Article IDe19923.

65. Zhou YY, Song HJ, Guo S, Wang Y, Gao HR, Zhang XJ, et al. A new triterpene from the green walnut husks of Juglans mandshurica Maxim. Journal of Natural Medicines. 2019; 13 (4): 99-102 (Doi: 10.1007/s11418-019-01309-4).

66. de Melo Gagliato D, Jardim DLF, Marchesi MSP, Hortobagyi GN. Mechanisms of resistance and sensitivity to anti-HE therapies in HER2+ breast cancer. Oncotarget. 2016; 39 (7): 64431-64446.

67. Azizian NG, Li Y. XPO1-dependent nuclear export as a target for cancer therapy. $J$ Hematol Oncol. 2020; 13: 61 (Doi: 10.1186/s13045-020-00903-4).

68. Hong AL, Tseng YY, Cowley GS, Jonas O, Cheah JH, Kynnap BD, et al. Integrated genetic and pharmacologic interrogation of rare cancers. Nature Communications. 2016; 7:11987 (Doi: 10.1038/ncomms11987). 
69. Kirli K, Karaca S, Dehne HJ, Samwer M, Pan KT, Lenz C, et al. A deep proteomics perspective on CRM1-mediated nuclear export and nucleocytoplasmic partitioning. Elife. $2015 ; 4$.

70. Thomas F, Kutay U. Biogenesis and nuclear export of ribosomal subunits in higher eukaryotes depend on the CRM1 export pathway. J Cell Sci. 2003; 116 (Pt 12):2409-19.

71. Muqbil I, Bao B, Abou-Samra AB, Mohammad RM, Azmi AS. Nuclear export mediated regulation of microRNAs: potential target for drug intervention. Curr Drug Targets. 2013; 14(10): 1094-100.

72. Kim J, McMillan E, Kim HS, Venkateswaran N, Makkar G, Rodriguez-Canales J, et al. XPO1-dependent nuclear export is a druggable vulnerability in KRAS-mutant lung cancer. Nature. 2016; 538 (7623):114-7.

73. Subhash VV, Yeo MS, Wang L, Tan SH, Wong FY, Thuya WL, et al. Anti-tumor efficacy of Selinexor (KPT-330) in gastric cancer is dependent on nuclear accumulation of p53 tumor suppressor. Sci Rep. 2018;8(1):12248.

74. Camus V, Miloudi H, Taly A, Sola B, Jardin F. XPO1 in B cell hematological malignancies: from recurrent somatic mutations to targeted therapy. J. Hematol Oncol. 2017; $10(1): 47$.

75. Taylor J, Sendino M, Gorelick AN, Pastore A, Chang MT, Penson AV, et al. Altered nuclear export signal recognition as a driver of oncogenesis. Cancer Discov. 2019; 9(10):1452-67.

76. Medina-Franco JL, Saldívar-González FI. Cheminformatics to Characterize Pharmacologically Active Natural Products. Biomolecules. 2020; 10 (11): 1566 (10.3390/biom10111566).

77. Prieto-Martínez FD, Arciniega M, Medina-Franco JL. Molecular docking: current advances and challenges. TIP Revista Especializada en Ciencias Químico-Biológicas. 2018; 21(Supl. 1): 1-23 (Doi: 10.22201/fesz.23958723e.2018.0.143).

78. López-López E, Naveja JJ, Medina-Franco JL. DataWarrior: An evaluation of the opensource drug discovery tool. Expert Opinion on Drug Discovery. 2019; 15: 13-17 (Doi: 10.1080/17460441.2019.1581170). 
79. Ertl P, Rohde B, Selzer P. Fast calculation of molecular polar surface area as a sum of fragment-based contributions and its application to the prediction of drug transport properties. J. Med. Chem. 2000; 43: 3714-3717.

80. Veber DF, Johnson SR, Cheng HY, Smith BR, Ward KW, Kopple, KD. Molecular properties that influence the oral bioavailability of drug candidates. J. Med. Chem. 2002; 45(12): 2615-2623.

81. Muegge I, Heald SL, Brittelli D. Simple Selection Criteria for Drug-like Chemical Matter. J. Med. Chem. 2001; 44 (12): 1841-1846.

82. Ghose AK, Viswanadhan VN, Wendoloski JJ. A knowledge-based approach in designing combinatorial or medicinal chemistry libraries for drug discovery. 1. A qualitative and quantitative characterization of known drug databases. J Comb Chem. 1999; 1: 55-68.

83. Lipinski CA, Lombardo F, Dominy BW, Feeney PJ. Experimental and computational approaches to estimate solubility and permeability in drug discovery and development settings. Adv. Drug Deliv. Rev. 2001; 46 (1-3): 3-26.

84. Kortagere S, Krasowski MD, Ekins S. The importance of discerning shape in molecular pharmacology. Trends Pharmacol Sci. 2009; 30(3): 138-147 (Doi: 10.1016/j.tips.2008.12.001).

85. Lagorce D, Douguet D, Miteva MA, and Villoutreix BO. Computational analysis of calculated physicochemical and ADMET properties of protein-protein interaction inhibitors. Scientific Reports. 2017; 7: 46277 (Doi: 10.1038/srep46277).

86. Arteca GA. Global measure of molecular flexibility and shape fluctuations about conformational minima. Journal of Computational Chemistry. 1993; 14 (6): 718-727 (CCC 0192-8651/93/060718-10).

87. Forrey C, Douglas JF, Gilson MK. The Fundamental Role of Flexibility on the Strength of Molecular Binding. Soft Matter. 2012; 8 (23): 6385-6392 (Doi: 10.1039/C2SM25160D).

88. Meng XY, Zhang HX, Mezei M, Cui M. Molecular docking: a powerful approach for structure-based drug discovery Curr. Comput. Aided. Drug. Des. 2011; 7: 146-57.

89. Du X, Li Y, Xia YL, Ai SM, Liang J, Sang P, Ji XL, Liu SQ. Insights into protein-ligand interactions: mechanisms, models, and methods. Int. J. Mol. Sci. 2016; 17: 144.

90. Dhorajiwala TM, Halder ST, Samant L. Comparative In silico molecular docking analysis of L-threonine-3-dehydrogenase, a protein target against African Trypanosomiasis using 
selected phytochemicals. J Appl Biotechnol Rep. 2019; 6(3): 101-108 (Doi:10.29252/JABR.06.03.04).

91. Santos MAB, Oliveira LFS, Figueiredo AF, Gil FS, Farias MS, Bitencourt HR, Lobato JRB, Martin YC. A Bioavailability Score. J. Med. Chem. 2005; 48: 3164-3170.

92. Mishra S, Dahima R. In-vitro ADME studies of TUG-891, a GPR-120 inhibitor using Swiss ADME predictor. Journal of Drug Delivery and Therapeutics. 2019; 9(2-s):366-369 (Doi: 10.22270/jddt.v9i2-s.2710). 